Historic, archived document

Do not assume content reflects current scientific knowledge, policies, or practices. 



\section{UNITED STATES DEPARTMENT OF AGRICULTURE}

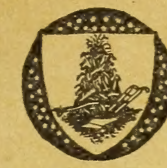

\section{DEPARTMENT BULLETIN №. 1486}

Washington, D. C.

$\nabla$

April, 1927

\section{HIGHWAY BRIDGE LOCATION}

By

C. B. McCULLOUGH, Briàge Engineer, Oregon State Highway Commission

in Cooperation with Bureau of Public Roads, United States

Department of Agriculture

\section{CONTENTS}

Page

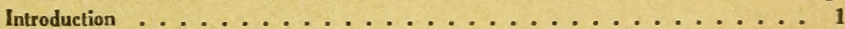

Location of Minor Structures ...................... 2

Cost Considerations Involved in the Location of Large Structures . . . . . . . 4

Maintenance Considerations Affecting Bridge Location . . . . . . . . . . . 13

Alignment Considerations .................. 20

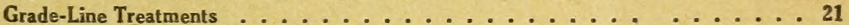

Traffic Influence on Bridge Location ................ 26

Location Over Navigable Waters ................. 27

\section{UNITED STATES}

GOVERNMENT PRINTING OFFICE

WASHINGTON 



\title{
UNITED STATES DEPARTMENT OF AGRICULTURE
}

\author{
DEPARTMENT BULLETIN №. 1486
}

Washington, D. C.

April, 1927

\section{HIGHWAY BRIDGE LOCATION}

By C. B. McCullough, Bridge Engineer, Oregon State Highway Commission, in Cooperation with Bureau of Public Roads, United States Department of Agriculture

\section{CONTENTS}

\begin{tabular}{|c|c|c|}
\hline ntroduction . . . & 1 & Grade-line treatments.... \\
\hline 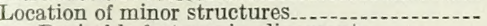 & & Horizontal alignment..... \\
\hline Desirable features in alignment & 3 & Structures on curves \\
\hline Undesirable features in alignment........ & 4 & Traffic influence on bridge location. \\
\hline Desirable features in culvert location & 4 & Through traffic considerations.- \\
\hline Undesirable features in culvert location.... & 4 & iderations _ \\
\hline ost considerations involved in the location of & & Local traffic considerations _ - \\
\hline large structures & 4 & ation over navigable waters \\
\hline Length of crossing & 4 & $\begin{array}{l}\text { Direction and velocity of currents, cross } \\
\text { currents, tidal flows, etc., as affecting the }\end{array}$ \\
\hline g-itions................. & 6 & horizontal clearance required \\
\hline Permanency of channel. & & Wind conditions as affecting horizontal \\
\hline Taintenance considerations affecting bridge & & Alignment of stream or waterway as affect- \\
\hline location & & ing sight distance for navigation \\
\hline hen & & Dock and wharf rights at the bridge head.- \\
\hline 1 movement of channel ... & & e above the bridge site. \\
\hline Effect of ice a & & Constriction of waterway by filled ap \\
\hline lignment considerations & & 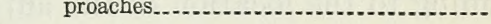 \\
\hline
\end{tabular}

\section{INTRODUCTION}

Bridge engineers have felt the need for a publication setting forth important principles governing bridge location, foundation investigations, and selection of type. Standard textbooks are satisfactory as to the structural design of bridges, but have been lacking on the above points. This bulletin deals with the first of these subjects and is the result of cooperative work between the Bureau of Public Roads of the United States Department of Agriculture and the Oregon State Highway Commission in Federal-aid road construction.

With the inception of any bridge project, the first duty of the bridge engineer is to investigate the site and to select the most economical crossing consistent with certain standards of quality as regards maintenance and operating conditions. It frequently happens, however, that the particular location which combines the above features to maximum advantage does not combine advantageously with the improvement project viewed as a whole. Some sacrifice in the selection of the bridge crossing is, therefore, necessary in order that it may more completely fit into the general location scheme. 
This may be illustrated by a crossing in southern Oregon. The logical site for the bridge and the one which was first chosen combined a very narrowly restricted neck in the river with exposed solid rock foundations. A steep, high cliff on one side of the stream furnished admirable support for an abutment at this point, thereby effecting a very marked saving in first cost. Unfortunately, however, it so happened that the adoption of a comparatively low level grade line necessitated intersecting the rock bluff at about half of its height. thus introducing several hundred feet of expensive rock cut. If, on the other hand, the grade line were raised to intersect the edge of the rim rock at its upper level, the far side of the approach would have been thrown off its support, thereby entailing a heavy expenditure for approach fills, involving rock borrow and overhaul. The only other feasible crossing involved a much greater river width and foundations on heavy gravel overlying bed rock, thereby entailing costly cofferdam construction. Comparative estimates embracing the bridge structure alone were such as to dictate the adoption of the first crossing by a large margin of saving. Comparative estimates covering the entire project, however, disclosed the fact that a distinct saving in the first cost could be made by adopting the more expensive bridge crossing in connection with the much less expensive approach construction.

The above is but one of many instances wherein a study embracing the entire crossing project (bridge and approaches) leads to conclusions quite different from those which would be the natural result of a study embracing the location of the structure alone. In view of this fact, therefore, it is felt that the matter of bridge location may be best treated by simply enumerating and discussing the various points of merit in location as affecting the first cost, maintenance, and operation of the structure itself, leaving it to each individual instance to balance such points of merit against similar points pertaining to the location of the adjacent portions of the project.

\section{LOCATION OF MINOR STRUCTURES}

For small structures, the location of the bridge or culvert itself is generally of importance secondary to that of the general alignment; in other words, it hardly ever pays to shift alignment to any marked extent as the accruing advantage is generally not worth the expense. In certain cases, however, waterway conditions even for minor structures may be greatly improved through a slight modification in location. As an illustration, consider Figure 1. The submitted or original alignment involves (1), a skew culvert crossing which is in itself undesirable from a standpoint of first cost on account of the increased length of barrel and should be eliminated if a straight crossing can be obtained, and (2) the construction of a long wing at $\mathrm{A}$ to eliminate the tendency to erode the fill during flood periods. This is another element of added first cost. The stream encroaches so near the shoulder of the road at B that it is quite possible that even the length of wing shown may not always prove adequate during a succession of future flood periods. This tendency to cut behind and under wing walls is the source of a great deal of serious trouble in the maintenance of small bridge structures whose location has not been made with attention to this detail. The examples shown on 
Plate 1, A and B, are typical of many instances of this kind. Unless this wing (fig. 1) is lengthened even more than shown, rip rap or some other form of bank protection is apt to be necessary at B. This is an element not only of added first cost, but of added maintenance cost as well. The channel change (shown dotted) might be a way out of the difficulty, but this is an item of added first cost and may or may not be cheaper than the skewed culvert and long wing. Moreover, the channel change affects a natural watercourse and the builder at once becomes liable for any property damage resulting from overflow and erosion which may take place at C.

All of the above undesirable features may be eliminated by adopting the revised alignment shown, and without introducing an added degree of curvature. This seems the logical way out of the difficulty but for the fact that the new alignment throws into the hill

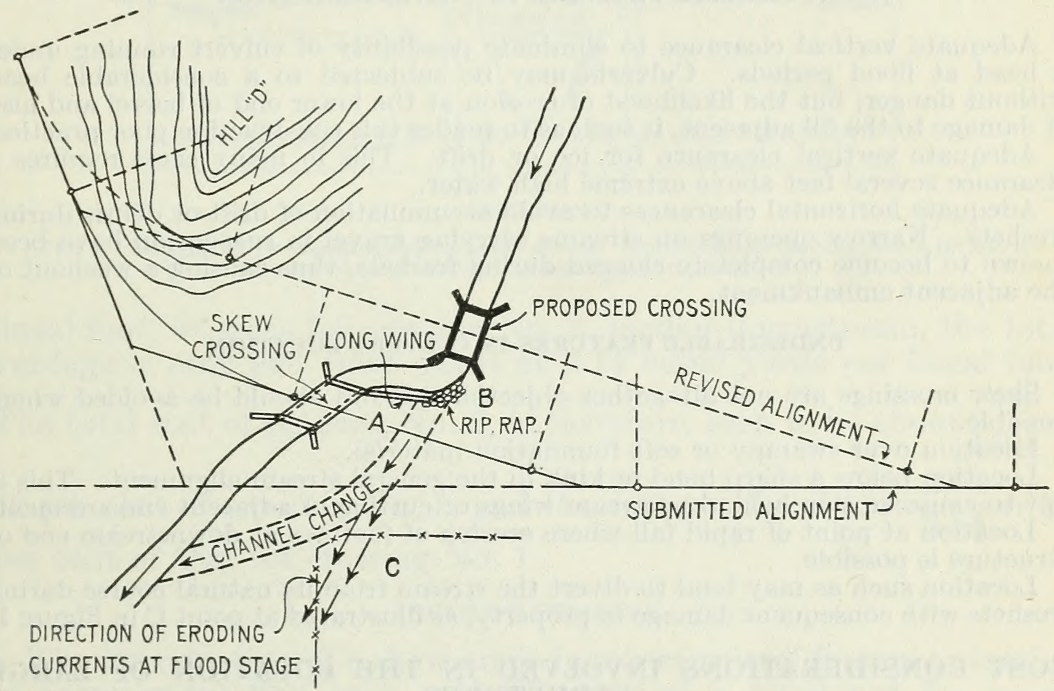

Fig. 1.-Small bridge structure as first located and relocation eliminating skew construction

at $\mathrm{D}$, thus involving more cutting and perhaps a more restricted sight distance around the curve. These last, then, are the considerations which must be balanced against the undesirable waterway features above enumerated. The solution will obviously depend upon the exact conditions disclosed by careful surveys and estimates along both lines, but the problem stated illustrates what may be encountered in the location of minor waterway structures. Each individual problem must, of course, be treated individually and solved on its merits. No fixed rules can be laid down, but the following points of merit and disadvantage may prove of assistance in studying any individual location problem.

\section{DESIRABLE FEATURES IN ALIGNMENT}

Maximum lengths of unbroken tangents.

Maximum possible clear sight distance around hill points.

Balanced earthwork quantities (cut and fill).

Minimum amount of overhaul.

Location through material easily and cheaply handled.

Minimum amount of rise and fall in grade line.

Easy horizontal curvature. 


\section{UNDESIRABLE FEATURES IN ALIGNMENT}

Location resulting in through cuts which are apt to drift full of snow in winter.

Location along sidehills of shifting or sliding material or along seepy or wet sidehills.

Location over swampy or seepy material or over ground where natural drainage is difficult or uncertain.

Location on sidehills having a north exposure. These are apt to be wet a greater portion of the time than sidehill cuts having the benefit of south exposure sunlight.

Adverse grade.

Sharp breaks in grade.

Blind curves or restricted sight distance.

Reverse curvature (on account of the difficulty of properly superelevating the roadway).

"Broken backs" or two curves in the same direction with a short connecting tangent.

\section{DESIRABLE FEATURES IN CULVERT LOCATION}

Adequate vertical clearance to eliminate possibility of culvert running under a head at flood periods. Culverts may be subjected to a considerable head without danger, but the likelihood of erosion at the lower end of barrel and also of damage to the fill adjacent, is such as to render this construction poor practice.

Adequate vertical clearance for ice or drift. This in many cases requires a clearance several feet above extreme high water.

Adequate horizontal clearances to avoid accumulation of drift or débris during freshets. Narrow openings on streams carrying gravel in suspension have been known to become completely clogged during freshets, thus causing a washout of the adjacent embankment.

\section{UNDESIRABLE FEATURES IN CULVERT LOCATION}

Skew crossings are not altogether objectionable but should be avoided where possible.

Location over swampy or soft foundation material.

Location below a sharp bend or kink in the general stream alignment. This is apt to cause erosion behind upstream wings or cutting of adjacent embankment.

Location at point of rapid fall where erosion of footings at downstream end of structure is possible.

Location such as may tend to divert the stream from its natural course during freshets with consequent damage to property, as illustrated at point $\mathrm{C}$ in Figure 1.

\section{COST CONSIDERATIONS INVOLVED IN THE LOCATION OF LARGE STRUCTURES}

For larger and more important construction, the matter of location for the bridge structure becomes increasingly important and tends more and more to outweigh considerations of cost as affecting the approach alignment. The following factors are among the many which should be considered in making a bridge location.

\section{LENGTH OF CROSSING}

Other things being equal, the location of a bridge structure should take advantage of any narrow neck or point of constriction in the waterway, due to steep, high banks. The two locations shown in Figure 2 illustrate the difference in cost which may accrue from this source. These are two crossings of the same river. Crossing No. 2 is several miles down stream from crossing No. 1, yet involves considerably less material, owing to the fact that advantage was taken of a steep, rock gorge of comparatively narrow width. Both crossings are over exposed rock, but the natural banks at the site of crossing No. 2 lend themselves to a shorter channel span, the channel being deeper as well as narrower, thus affording greater waterway area for 
equivalent horizontal span. The overflow banks at the site of crossing No. 2 are also higher with reference to flood-water elevation, so that a shorter approach structure is permissible. The yardage of concrete for crossing No. 1 is 1405 cubic yards or 2.44 cubic yards per
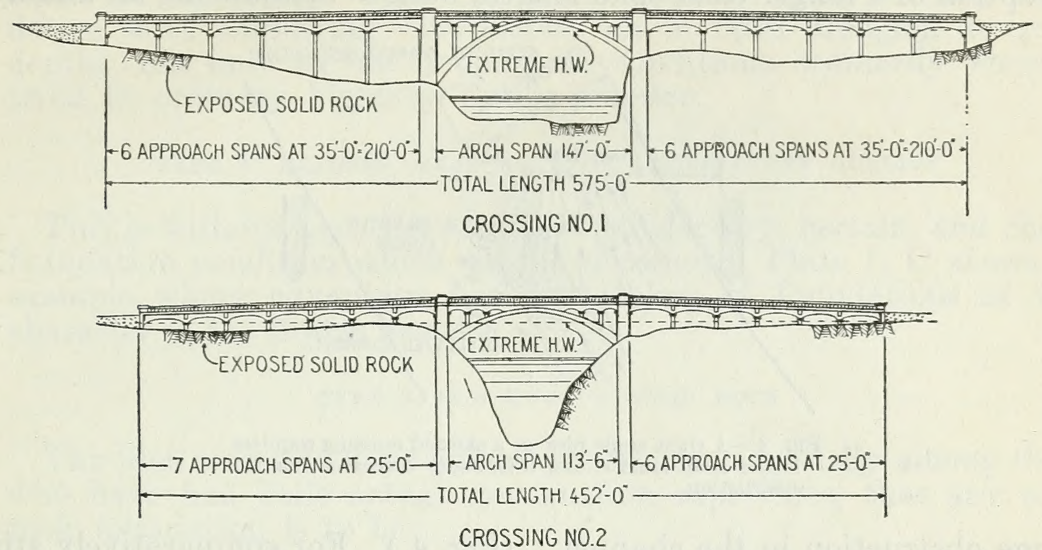

FIG. 2.-Designs for two crossings of the same stream. Conditions at crossing No. 2 permit a design of considerably less cost than at crossing No. 1

lineal foot, whereas for crossing No. 2, farther downstream, the total yardage is only 969 cubic yards or 2.14 cubic yards per lineal foot. The total cost of crossing No. 2, is therefore, seen to be about $\frac{969}{1405}$ or 69 per cent of crossing No. 1 , and the cost per lineal foot $\frac{2.14}{2.44}$ or 88 per cent of that for crossing No. 1 .

\section{ANGLE OF CROSSING}

The introduction of a skew angle involves several factors operating to increase the first cost. (1) Where steel is employed for superstructure work the price per pound is generally slightly more, owing

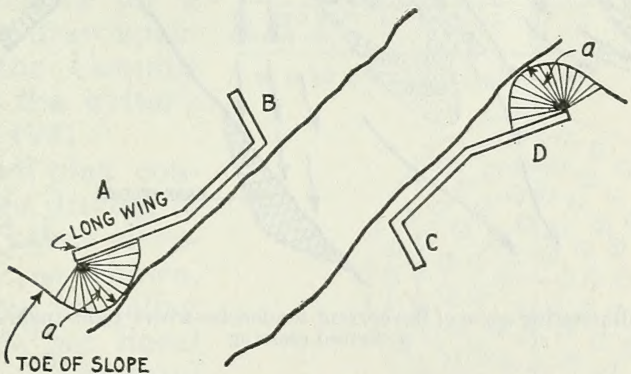

FIG. 3.-Diagram illustrating length of wing wall required to prevent erosion at toe of slope

to the cost of fabrication. The weight may prove to be greater than that of a square span of equal length. This will be true if the floor beams are placed parallel to the piers, as is sometime done. (2) The piers and abutments will be increased in length and the wing walls on 
abutments will need to be longer on two of the four corners. If the wing walls designated as A and D in Figure 3 are not sufficiently long: to keep the toe of the slope out of the stream, the toe will be eroded.

The use of right angle piers on a skewed crossing necessitates the adoption of a longer clear span length, besides introducing an unduly

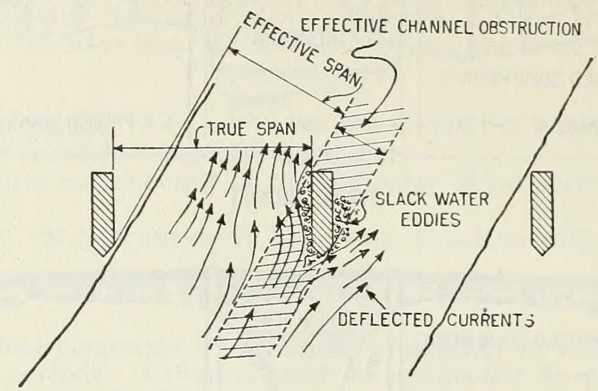

FIG. 4.-A right angle pier on a skewed crossing requires longer span lengths and introduces excessive channel obstruction

large obstruction in the channel. (Fig. 4.) For comparatively still or sluggish streams, right angle piers on skewed crossings have been successfully used in many instances. For current water, however, this practice leads to excessive maintenance for bank protection, and to the accumulation of drift with danger of local erosion. Figure 5 illustrates some of the tendencies where right-angle piers are used on skewed crossings.

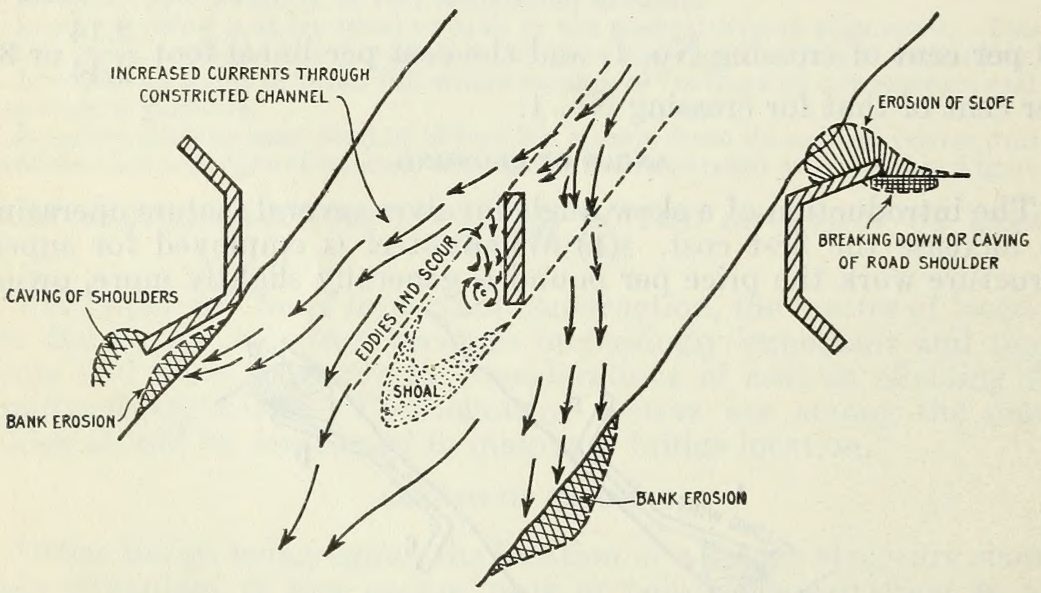

Fig. 5.-Diagram illustrating some of the current tendencies where right-angle piers are used on a skewed crossing

\section{FOUNDATION CONDITIONS}

Many times the range of choice in the location of a bridge may involve several kinds of foundation conditions. In order to properly balance the various merits of each location, it becomes necessary to know the relative advantages of these various types of foundation conditions. It is impossible to formulate any definite or fixed rules 
for judging the relative merits of different conditions, these being to a large degree modified by the nature of the individual problem. The following brief discussion of the most frequently encountered foundations may, however, prove enlightening as far as general principles are concerned. This discussion does not apply to deep foundation work employing compressed air or open dredging to great depths, but only to the foundation conditions ordinarily encountered in ordinary highway bridge practice.

TYPE A. EXPOSED SOLID ROCK OF SATISFACTORY QUALITY

This is without question the most satisfactory, certain, and cheap foundation condition which can be obtained. Plate 1, C shows an example where advantage has been taken of foundations of this character in the bridge location.

\section{TYPE B. SUBAQUEOUS SOLID ROCK}

The idea seems to have gained prevalence, especially among those who have had little actual construction experience, that any solid rock foundation is to be preferred to softer material at the same depth. This, however, is far from true, in fact, for subaqueous work, the presence of solid rock under certain conditions may entail an expense much greater than if a reasonably stiff clay were encountered at the same depth. This point is illustrated by Figure 6, which is a sketch showing the principal dimensions of the center pier for a 239-foot steel-draw span, built over the Coquille River under the writer's direction, in 1921.

The original plan contemplated the driving of timber piles below elevation -18.0 as shown. The bid price on piling was 40 cents per lineal foot in place. The total weight of the center pier and superstructure resting thereon was $1,348.75$ tons. From elevation -18.0 to elevation -30.0

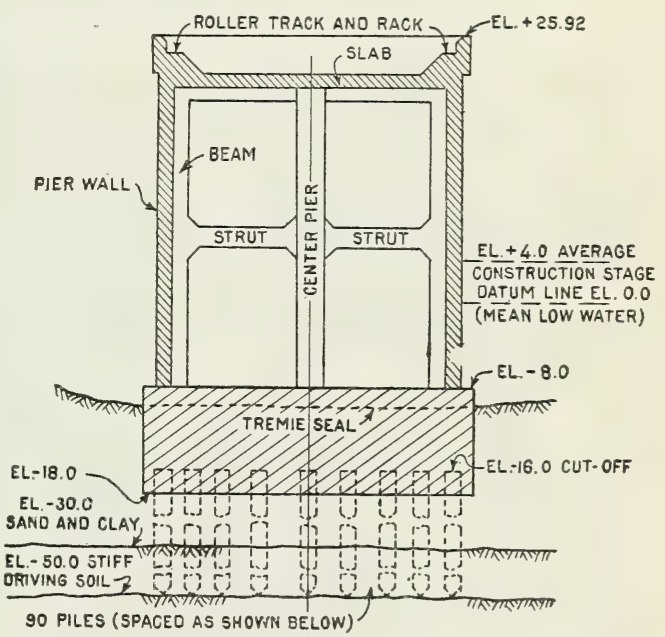

the soil encountered was a sand-clay mixture with insufficient resistance to afford lateral stability to piling. When the work on 
the piers was started, it was thought that the soil between elevations -30.0 and -50.0 would be such as to admit the penetration of piling for a sufficient distance to insure adequate lateral support. Figure 6 illustrates the condition expected. Instead of this formation,

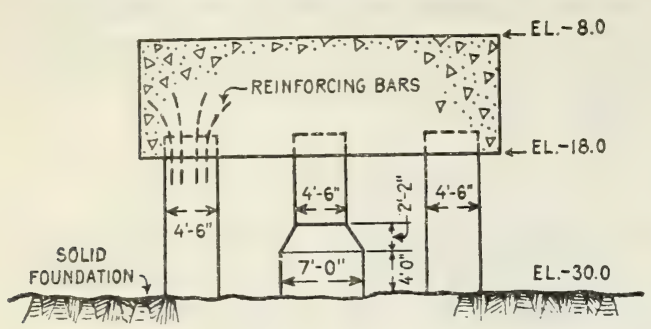
solid foundation material (cemented gravel) was encountered at elevation -30.0 , and owing to the fact that the superimposed load was a moving one, it was considered the part of prudence to redesign the foundation to insure maximum lateral stability.

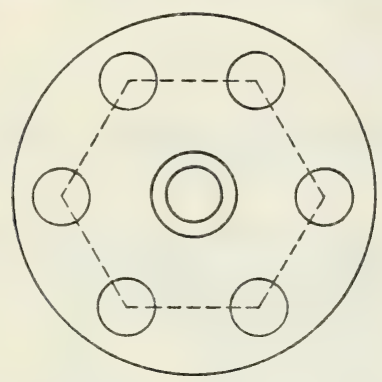

FrG. 7.-Redesign of pier for swing span over Coquille River necessitated by encountering solid foundation at elevation -30.0. This design cost considerably more than the first design in which it was anticipated that piles could be driven. After several tentative redesigns had been prepared, the scheme shown in Figure 7 was finally adopted as the cheapest possible solution. This method of construction utilized seven steel tubes carried to solid rock and filled with concrete, as shown in Figure 7 . The following is a comparison of cost for the two types of foundation.

Scheme No. 1.-(Possible if stiff clay had been encountered at elevation - 30.0.) Total weight of structure above elevation $-18.0,1,348.75$ tons. Number of piles necessary at 15 tons per pile, $\frac{1,348.75}{15}=90$. Assuming a penetration to elevation -50.0 , the total quantity of piling needed would be $90 \times 34=3,060$ lineal feet, and at 40 cents per foot the cost would be $\$ 1,224$.

Scheme No. 2.-(Possible for soft rock or hardpan at elevation -30.0.) Total area of base needed at 10 tons per square foot unit load would be 134.8 square feet.

Six tubes with $4 \frac{1}{2}$-foot diameter and one central tube with a 7 -foot diameter give a combined area of

$$
\begin{aligned}
& \frac{(4.5)^{2} \pi}{4} \times 6=95.5 \\
& \frac{(7.0)^{2} \pi}{4}=\frac{38.4}{133.9} \text { square feet. }
\end{aligned}
$$

The following is the actual cost of the work constructed as indicated in Figure 7:

Steel tubular caissons in place 22,980 pounds, at 9 cents _. _. _. _. $\$ 2,068.20$

Excavation in tubes, 59.5 cubic yards, at $\$ 6$

Concrete in tubes, 55.33 cubic yards, at $\$ 25$

$1,383.25$ 
In other words the encountering of rock or hardpan at elevation -30.0 increased the cost of this work from $\$ 1,224$ to $\$ 3,808.45$. Of course, if the foundation encountered had been hard rock, a higher unit load on the foundation could have been employed and some saving made thereby. The cost, however, could not have been brought down to the cost of the piling foundation.

Subaqueous rock foundations are grouped in the order of their desirability as follows:

(1) Exposed rock in still water at shallow depths.

(2) Rock overlaid with a stiff impermeable cover.

(3) Rock overlaid with a stiff permeable cover.

(4) Bare rock in still water and comparatively deep.

(5) Bare rock in swift current water and comparatively deep.

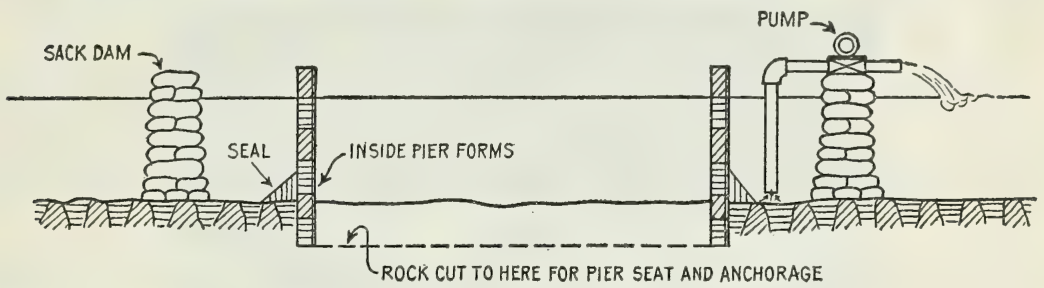

FIG. 8.-Sack dam used in foundation work on rock at shallow depths and where the current is not strong

Class 1 admits of the construction of cheap sack dams as shown in Figure 8. After these are constructed they may be unwatered easily and calked or plastered either from the inside or outside to stop any large leaks. The rock surface can be worked to roughen and to "heel in" the pier base and back forms may be built and easily sealed at the bottom as shown. This type of construction may be used for depths such as can be held by sack dams and in currents which are not too swift to permit working around the sack dam.

Classes 2 and 3 are illustrated in Figure 9. Where the cover is impermeable, as indicated

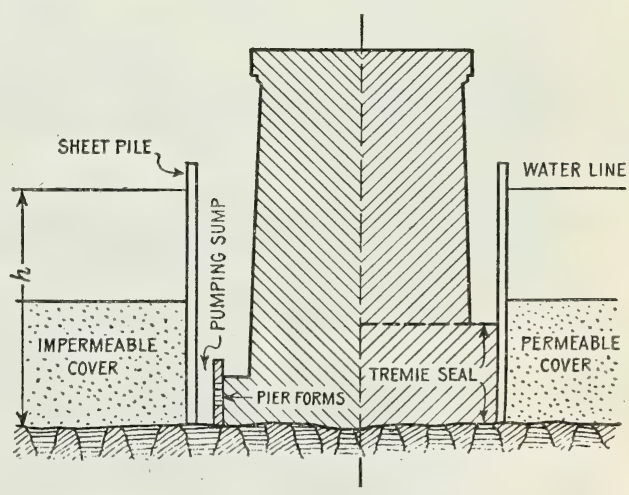

FIG. 9.-Methods of pier construction where rock is overlaid by permeable and impermeable cover at the left, the foundation may be kept dry by intermittent pumping from a sump located between the sheet piling or crib and the pier forms and no seal is necessitated at the base. Where the cover is permeable, as shown at the right of Figure 9, a tremie or bottom-dump bucket seal of thickness sufficient to withstand the hydrostatic head $h$ must be placed before the dam can be unwatered. This seal must, in general, be of a thickness equal to $\frac{62.5}{150} h$, or about $0.4 h$. For great depths, the cost of this seal becomes very high and for very great depths the use of the pneumatic caisson is more economical. 
With classes 4 and 5 where the rock surface is bare, the cofferdam construction becomes more costly. Even with a permeable cover, it is generally possible to get enough sealing effect outside the dam for unwatering for the short time sufficient to inspect the rock surface. For bare rock, however, this can be accomplished only by the construction of a double-walled puddle dam, as shown in Plate $1, \mathrm{D}$, which is very expensive, or by the use of a submarine diving outfit, which is also costly. It is very essential that bare rock foundations be inspected in the dry, if possible, and also that the masonry be well "heeled in"- generally from 8 to 30 inches into the solid rock if the current is swift.

TYPE C. GRAVEL OR BOWLDERS AT A REASONABLE DEPTH, WHERE A PENETRATION OF A FEW FEET INTO THE SAME IS SUFFICIENT TO GUARD AGAINST EROSION

Footings on this material must, in general, be larger than on solid rock; on the other hand the placement of sheeting or cofferdams is many times easier than on solid rock, since it is possible to drive the sheeting into the substrata a sufficient distance to brace it at the bottom.

TYPE D. MATERIAL WHICH IS SOFT ENOUGH TO PERMIT THE DRIVING OF PILES, YET STIFF ENOUGH TO AFFORD LATERAL STABILITY

This type of foundation requires an area of not less than 2.5 by 2.5 feet, or 6.25 square feet for each pile used. For a 20 -ton bearing per pile this is equivalent to that of a natural soil of about 3 tons per square foot bearing capacity. For locations exposed to excessive erosion, this type of foundation affords a greater insurance against scour than does one on a gravel or bowlder formation, unless the latter is carried to a depth as low or nearly as low as the bottom of the piling which would in general result in a much higher first cost than the pile foundation.

TYPE E. VERY SOFT MATERIAL OF A CONSIDERABLE DEPTH OVERLAYING A HARD AND IMPENETRABLE SUBSOIL

This type of foundation precludes the use of piling on account of the lack of lateral stability. Resort must be had to the sinking of individual tubes or piers well heeled into the solid or to the carrying of the entire foundation down to solid material. (Fig. 7.)

\section{TYPE F. BOWLDERS OR LOOSE ROCK AT A GREAT DEPTH OF WATER}

This is one of the most difficult foundation conditions encountered. Piling can not be driven. Difficulty is almost always encountered in excavating within a crib and in founding a crib in such manner as to make it possible to unwater the cofferdam. On the other hand, it is not the part of prudence to found on such material without a thorough inspection, preferably in the dry, and the removal of all loose material. Where the water is swift, footings must be anchored against lateral movement or sliding along inclined rock or bowlder surfaces, and this anchorage can be accomplished best only in the dry.

In weighing the relative merits of the various types of foundation conditions, as above outlined, the following facts should always be borne in mind:

A sheet pile cofferdam is generally cheaper than a crib of like dimensions if it can be used. 


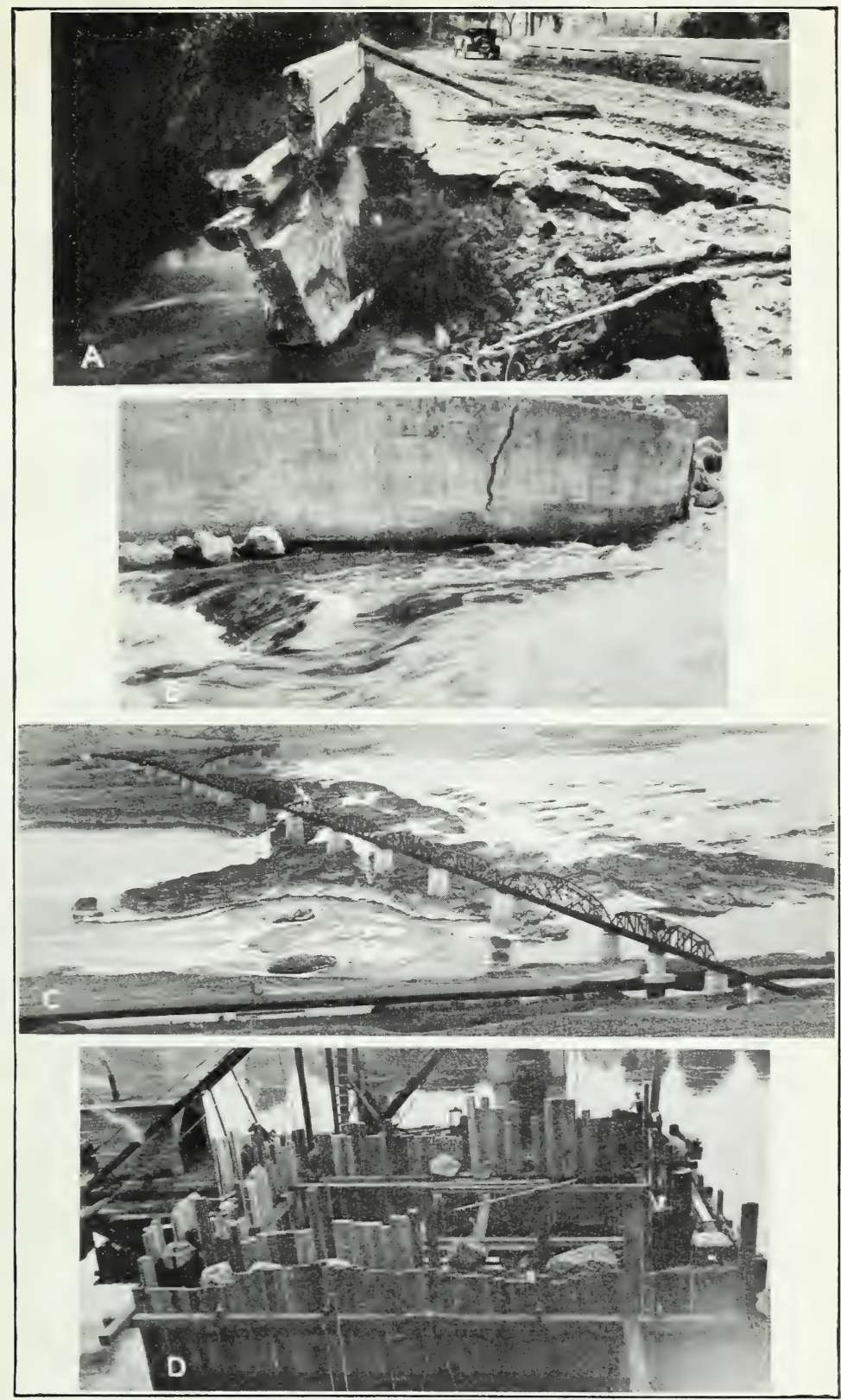

\section{Examples of Damage to Bridge Structure by ERosion}

A.-Failure of wing wall due to improper design and location

B.-Undermined wing wall, primarily the result of poor location

\section{EXAMPLES OF DIFFERENT FOUNDATION CONDITIONS}

C.-Railroad bridge over the Columbia River at Celilo, Oreg. This is a good example of site selection based on foundation conditions. Every pier is on exposed solid rock, a condition not encountered at any other crossing within the zone of selection D.-Double wall puddle dam construction on Oregon City bridge. This type of construction was made necessary by solid rock foundation without overburden and at too great a depth to permit the use of a simple sack dam 


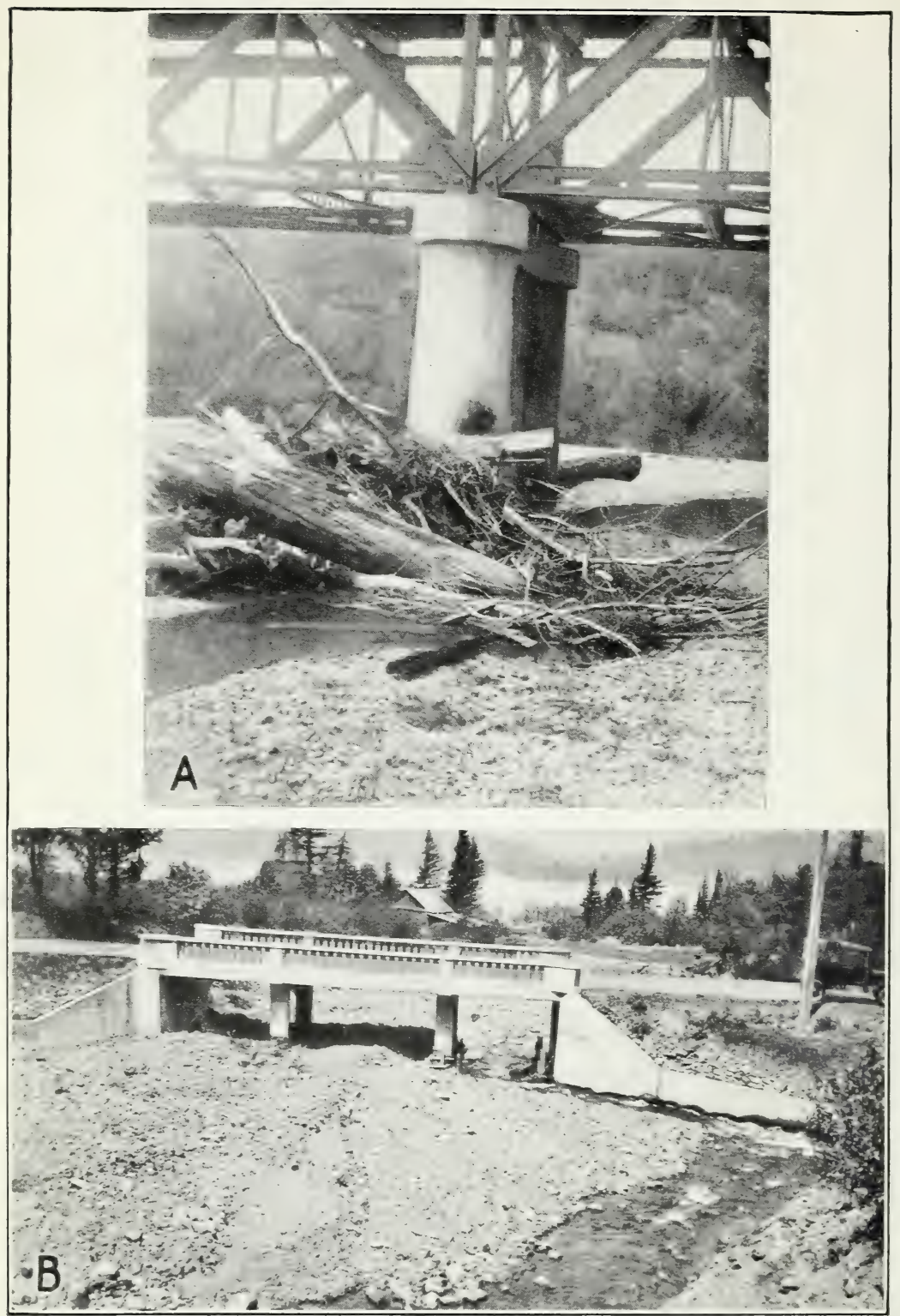

DRIFT ACCUMULATIONS AND Bars Formed BY THE STREAM MAY DEFLECT THE CURRENT SO AS TO CAUSE EROSION

A.-Drift accumulation against shore pier left by receding flood. At the next high water this drift may deflect the current in such a way as to cause damage by erosion

B.-Deposit of gravel and sand left hy a stream which has a steep gradient on its upper reaches. When the stream emerges on a flat near its mouth the current is slackened and deposition takes place. During a 5-year period this stream has moved across the channel three or four times. At the present time it impinges against the right wing, requiring riprap protection 
For any type of foundation, except piling, the cost increases nearly as the square of the depth below water surface.

Crib work on a pile foundation need not be unwatered, but can be sealed with concrete placed with a tremie or bottom-dump bucket. Footings through semisolid material, such as stiff clay or gravel resting on solid rock overlaid with such material may be similarly placed, since the overburden affords the necessary lateral support. Footings on bare rock or on rock overlaid with soft material must be anchored laterally, for which purpose it is generally necessary to excavate into the rock a short distance. For this reason, and also to avoid the danger of founding upon inclined rock surfaces or large loose bowlders, it is generally necessary to unwater foundations of this kind.

For relatively great depths, the cost of a concrete seal of sufficient thickness to resist the hydrostatic head during construction is a large item. Considerable saving may then accrue if an impermeable or nearly impermeable material is encountered, as in this case the water surface surrounding the cofferdam may be kept lowered by means of a double wall dam or an auxiliary pumping pit, until the concrete in the footing base has been placed.

In making a bridge reconnaissance, the engineer should bear in mind that exposed rock at the water's edge, even if both banks of the stream disclose the same formation, does not always indicate a rock bottom extending across the channel. There are numerous instances where a stream during a former geologic period has cut a deep gorge which during a subsequent period has been filled with a lava flow or with glacial, or alluvial débris. The Hudson River is a classic example of this action. Here the river gorge has been filled to a depth of a thousand feet due to a general land subsidence which converted the lower reaches of the river into an estuary or bay in the comparatively still water of which a general sedimentation occurred. A later reelevation of the land

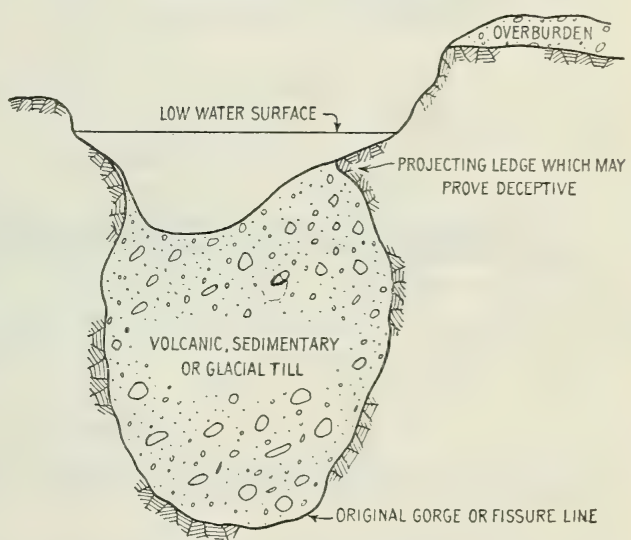

FIG. 10.-A buried channel or fissure formation

reconverted the bay into a river and the flow during the present period is through and over the sedimentary deposit which overlies the original gorge floor for a depth of a thousand feet or more. In certain areas in the West, deep rock-bound gorges have been partially filled through subsequent lava flows and in the glaciated sections glacial gravels or glacial till is found filling up old buried channels in the original rock formation.

In certain instances river gorges have had their origin in a fissure formation or in the comparatively rapid erosion of intrusive dikes of material softer than the surrounding rock.

In view of the foregoing, a condition as indicated in Figure 10 may quite possibly be encountered. In such a case, it might easily be possible to mistake the overhanging edge of the buried channel for solid rock bottom, and to form the conclusion that this formation extended clear across the stream. A careful investigation of the general characteristics of the river gorge should be made before judgment is passed upon foundation conditions. 
Conditions as shown in Figure 10 are apt to be encountered:

Where a river gorge has become sedimented due to land subsidence or other geologic action converting streams into lakes or bays.

Where lava flows have filled up river gorges of a former period.

Where drift deposits in glaciated country have obliterated prior channels.

Where the river gorge has had its origin in a volcanic fissure.

Where the river gorge is cutting through an intrusion of soft lava or a deposit of volcanic ash.

\section{PERMANENCY OF CHANNEL}

In general, any movement or shifting of a stream channel is a factor which operates to increase maintenance costs rather than first cost of construction and this factor will be discussed more fully under maintenance considerations. In the matter of first cost, however, shifting or meandering streams do many times necessitate a longer crossing than would be necessary to carry maximum flood discharge. Crossings over such streams are also apt to be more expensive, owing to

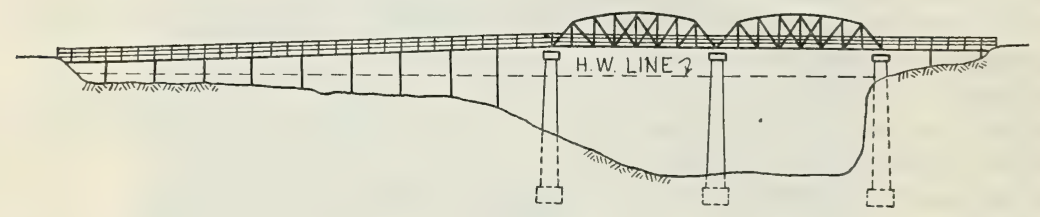

DESIGN A

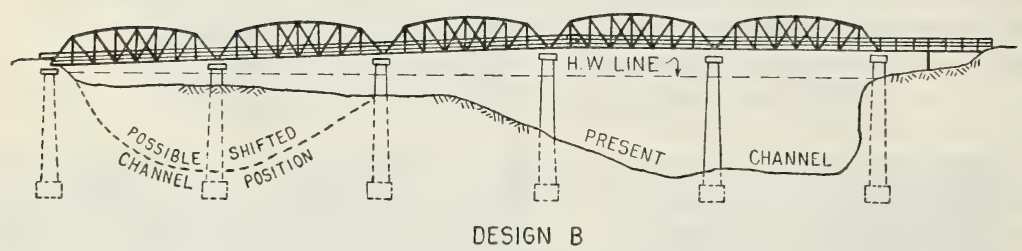

FIG. 11.-Two designs for the same location. Design $\mathrm{A}$ is based on the assumption that the main channel will remain fixed, whereas design $\mathrm{B}$ is based on the assumption that the channel may shift

the necessity for long span and deep pier construction from side to side of the flood plain a larger portion of which construction could, were the stream stable, be replaced by much less expensive viaduct construction. In Figure 11, design $\mathrm{A}$ is a typical crossing of a main channel having a stable right-hand bank and its entire flood plain on the other side. If the main channel is stable and permanent, two river spans will suffice and the balance of the flood plain may be bridged with viaduct construction at a considerable less cost per linear foot. If, however, the stream channel is likely to shift from side to side of the flood plain during the estimated life of the bridge, construction as shown in design $\mathrm{B}$ will be necessitated. In the latter case, six stream piers are needed as against three and five steel spans as against two.

In view of the foregoing, a careful study should be made for bridge crossings over meandering or shifting streams and a site chosen where conditions are to the greatest possible extent favorable to channel permanency. 


\section{MAINTENANCE CONSIDERATIONS AFFECTING BRIDGE LOCATION}

\section{SCOUR AROUND PIERS}

Probably one of the largest single items of maintenence cost for bridges is the protection of footings against scour, or the repairing: of damage already done by erosion. It is, therefore, desirable to so select the site for each crossing as to eliminate such tendencies, as far as possible.

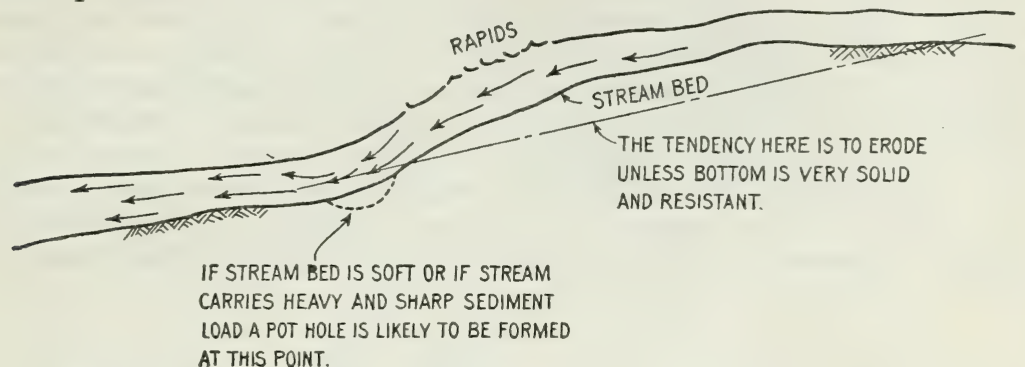

FIG. 12.-Stream profile showing points at which erosion is likely to occur

In general, scour or erosion may be expected:

(1) Wherever there are vertices in the stream bed profile in connection with a stream bed of erodable material. Figure 12 illustrates a stream profile of this kind. Generally a rapid will be observed just below the grade vertex. This rapid will generally possess a tendency to move upstream as the vertex behind it is eroded back. Just below the rapid the erosion of a pot hole is quite possible. The cause of pot-hole formation generally lies in the occurance of eddies or whorls carrying sharp cutting sediment.

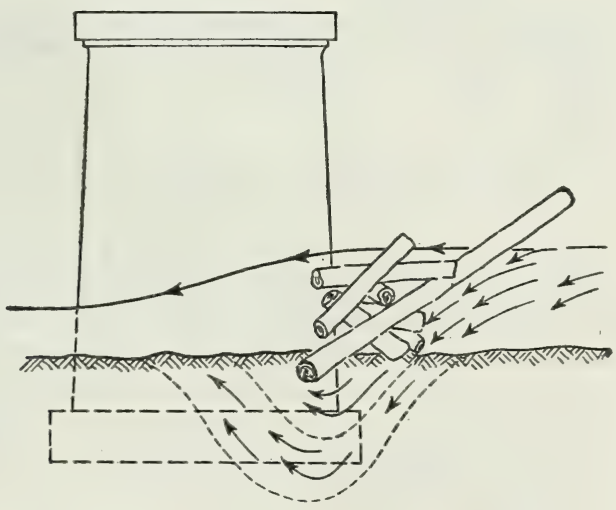

FIG. 13.-Action of drift accumulation in causing scour

(2) When any artificial obstacle like drift or ice deflects flood currents downward against the footings. (Fig. 13 and pl. 2, A.)

(3) When the bottom, for a considerable distance below the surface is very soft, or, in case of harder bottoms, when the stream carries a large quantity of sediment which acts as an abrasive. In this latter case, there must of course be sufficient current velocity to carry the sediment load else bar formation will occur. 
(4) Where there is a soft bottom and the depth at flood stage is very large in proportion to the normal depth.

In explanation of the last item, for streams (like the Colorado River) having a very soft bottom and wide fluctuation of stage the bottom is constantly moving. As the stream rises the increased bottom currents erode and pick up the bed material, dropping it as the flood crest recedes. For conditions of this kind the bed of the stream may move downward as much as 2 feet for every foot rise in water stage. This movement of the channel bottom is distinguished from other erosive action in that the movement is a constant fluctuation-in fact it may be termed an "elastic movement" of the channel, to accommodate itself to changing hydraulic conditions.

(5) Where there is a constriction of the waterway coupled with a bottom of erodable material the power of a stream to erode varies as the square of its velocity so that any channel constriction operating to increase the current velocity increases the eroding power of

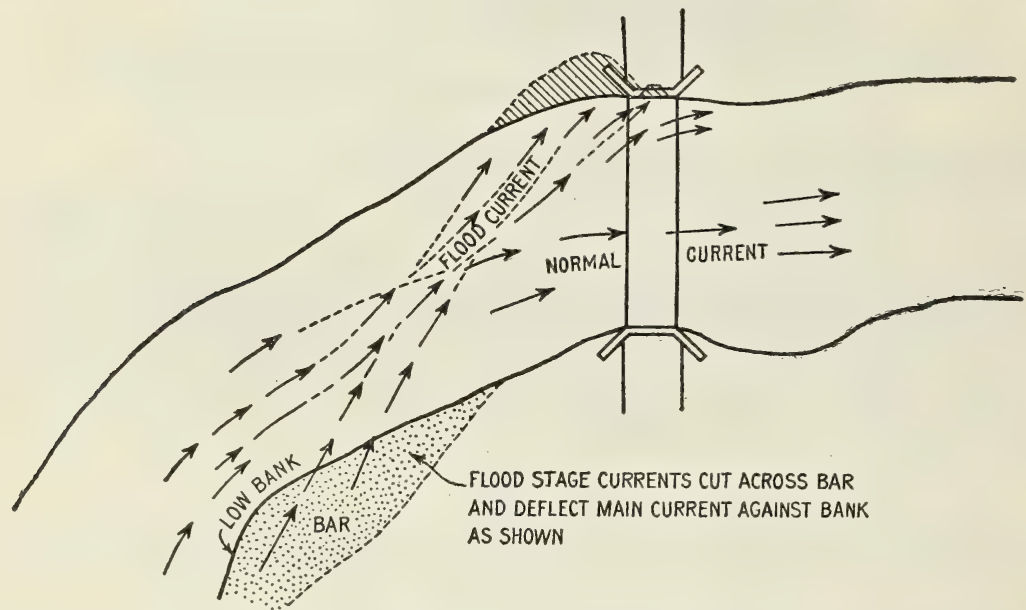

FIG. 14.-A typical example of normal and flood current action at a bend in a stream

the stream. In general, every material has a definite velocity at which it starts to erode. Silt and fine sand, moving at a comparatively low velocity, gravel at a higher velocity, and so on.

For shallow streams, soft silt bottoms will generally erode at a bottom velocity of less than one-half foot per second, sand bottoms at a velocity of from 1 to 1.5 feet per second, ordinary clay at a velocity of about 2 to 3 feet per second, compact clay at a velocity of 5 to 6 feet per second, and heavy gravel at a velocity of about 4 to 6 feet per second.

(6) At points where there is bend in the channel (fig. 14) which directs a current of considerable velocity against one pier or abutment.

\section{SHIFTING OR LATERAL MOVEMENT OF CHANNEL}

A crossing site to insure stability of the stream channel should, in general, be at a point where the stream runs between well-defined banks. These banks must be of comparatively resistant material. 
Flood currents must be parallel to the bank lines unless the banks are high and of solid rock or other exceptionally resistant strata. The stream bottom must be fairly hard and the wet perimeter should be small in comparison with the cross-sectional stream area. The average depth should, in general, be large in comparison with the maximum depth.

Stream development may be said to have its geologic origin in the formation of the first gulley or wash where water has fallen upon any hillside. As the run-off concentrates along lines of steepest slope, these gulleys are cut deeper and are extended first headward and later laterally. The extension of one gulley or gorge operates to intercept and cut off the drainage flow from adjacent, lesser gulleys, so that gradually out of the numerous small and independent drainage channels one principal system is evolved and thus a stream is formed.

In the early or youthful stages of development the stream is characterized by its rapid fall, steep banks, comparatively few tributaries, and general tendency to erode or cut vertically. The geologist has designated streams in this stage of development as "youthful" streams and the drainage basin as "young topography."

As the development progresses, the stream bed gradually cuts to grade, or base level, meeting the grade of its discharge outlet (sea level or lake level, as the case may be) at its mouth and extending back therefrom in a form which approaches roughly a vertical parabolic curve. The slope along the upper reaches will therefore be comparatively steep while near its mouth the stream grade has flattened out, approaching a level.

The power of a stream to erode varies as the square of the velocity for any given bed material, whereas the ability of a stream to transport the sediment which it has eroded varies as the sixth power of the velocity and also to a certain extent with the volume of stream discharge, a larger stream, being able to carry a greater sediment load than a smaller one, at the same velocity. The upper or steeper reaches of the stream, therefore, will be eroding and transporting sediment to such an extent as to bring to the less rapid lower river more load than it can transport so that some of the sediment may be deposited. Such a condition is indicated in Plate 2, B.

As the stream continues to develop, lateral erosion tendencies widen the valley floor, forming flood plains of considerable expanse. The topography loses its original rugged outline, the stream becomes more sluggish, and the waterway and adjacent topography is said to have passed from youth into maturity.

Streams which have eroded to base level and have, through a succession of years cut a broad flood plain, are very apt to be extremely unstable as regards lateral movement of channel. Such streams in general show a marked tendency to shift back and forth from one side of their flood plain to the other, as shown in Figure 15. The general tendency seems to be an oscillation back and forth from one side to the other in a series of broad bends which progress gradually downstream. The general sequence of stream movement in cases of this kind may be observed from a study of Figure 15. The original bank lines are shown by the solid lines in the illustration. During the first flood water the bank at D is quite apt to be eroded. As the stream rises, the velocity at $\mathrm{D}$ is increased, the cutting power is 
increased and the stream bank on the conrex side of the stream takes the position DEF. This new path is longer than the original path and the relocity soon drops slightly as a result of the change. On the concare side of the stream, where velocity is lowest, a bar starts forming. As the flood recedes more sedimentation occurs and the bar is extended along points of least velocity. The next flood will probably cut the channel from the position DEF to the position $\mathrm{DEF}^{\prime}$. In the meantime, the convex stream bank below has moved to the dotted position and bars have formed on the upper shore through exactly the same process, Thus through a series of floods

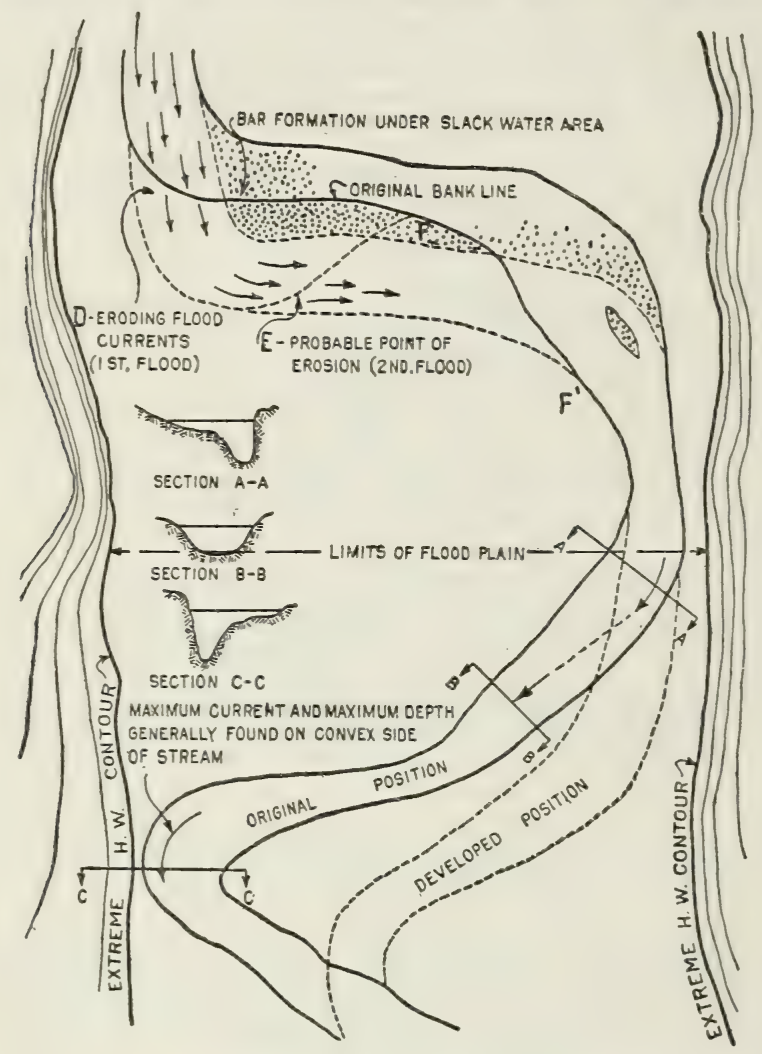

FIG. 15.-Channel change in a stream with wide flood plain due to erosion

the tendency will nearly always be for movement as shown in Figure 16. In general the principal channel current and also the deepest part of the channel will be found on the convex side of the stream.

The above represents the general tendency for the stream as a whole. In addition there will be local erosion, shifting and cutting at many points due to cross currents, whorls, eddies, etc., these tending to erode at one point and silt up at another, so that the future behavior of any stream at any given point can only be predicted after a careful study. In general, for any structure of material size, it will pay to go into the matter of location very thoroughly, studying the direction, velocity, and effect of flood currents at different 


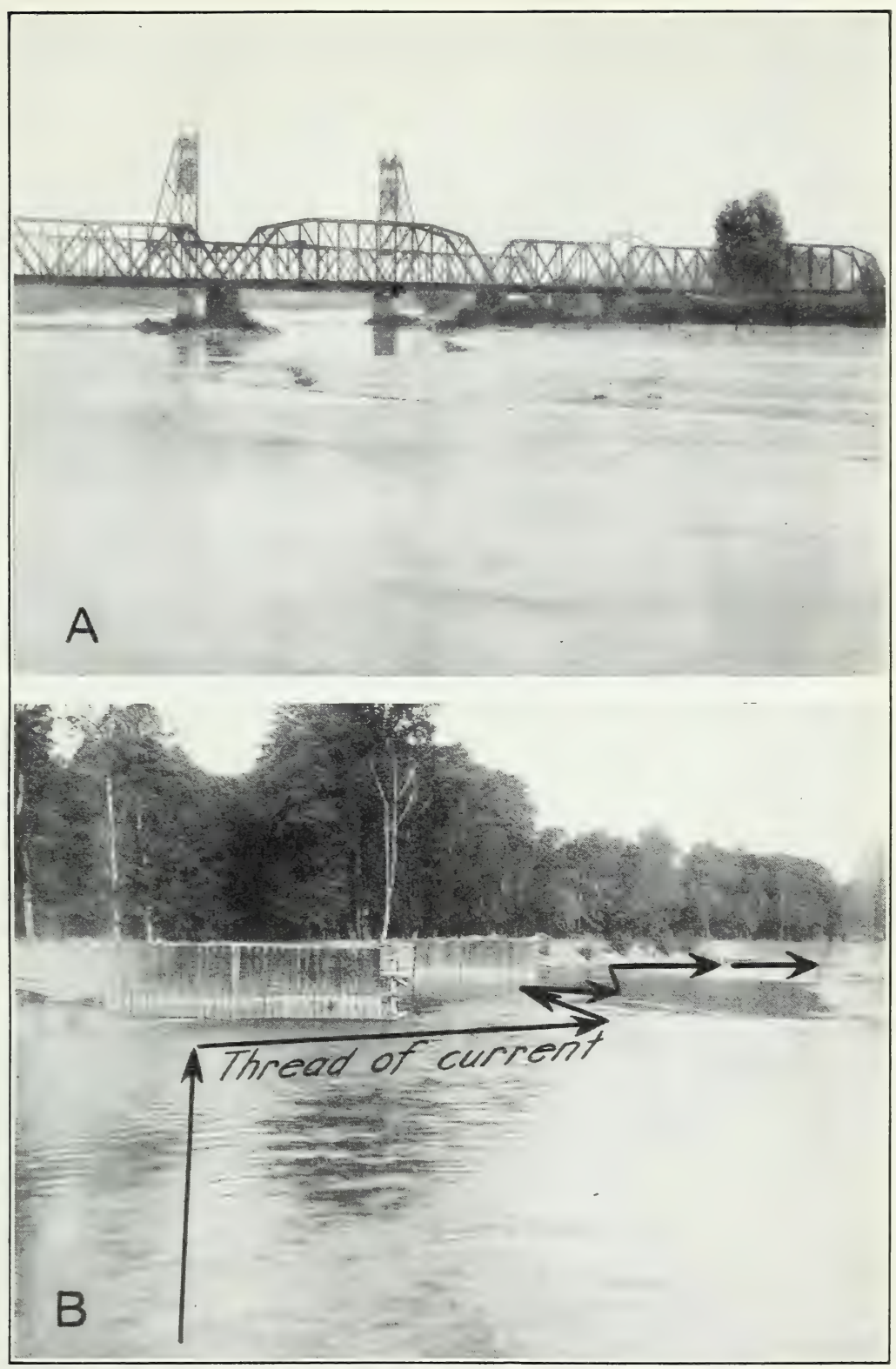

\section{Examples of Channel Movement and Control}

A.-The channel of the Willamette River has changed to such an extent that the old swing span shown at the right is now over dry land. The channel is still progressing toward the left

B.-Wing dams deflect the current outward but on striking the main body of water the current is redeflected inward. For this reason wing dams are frequently not as satisfactory as bank riprap unless a series of dams is carried completely past the limits of current attack 


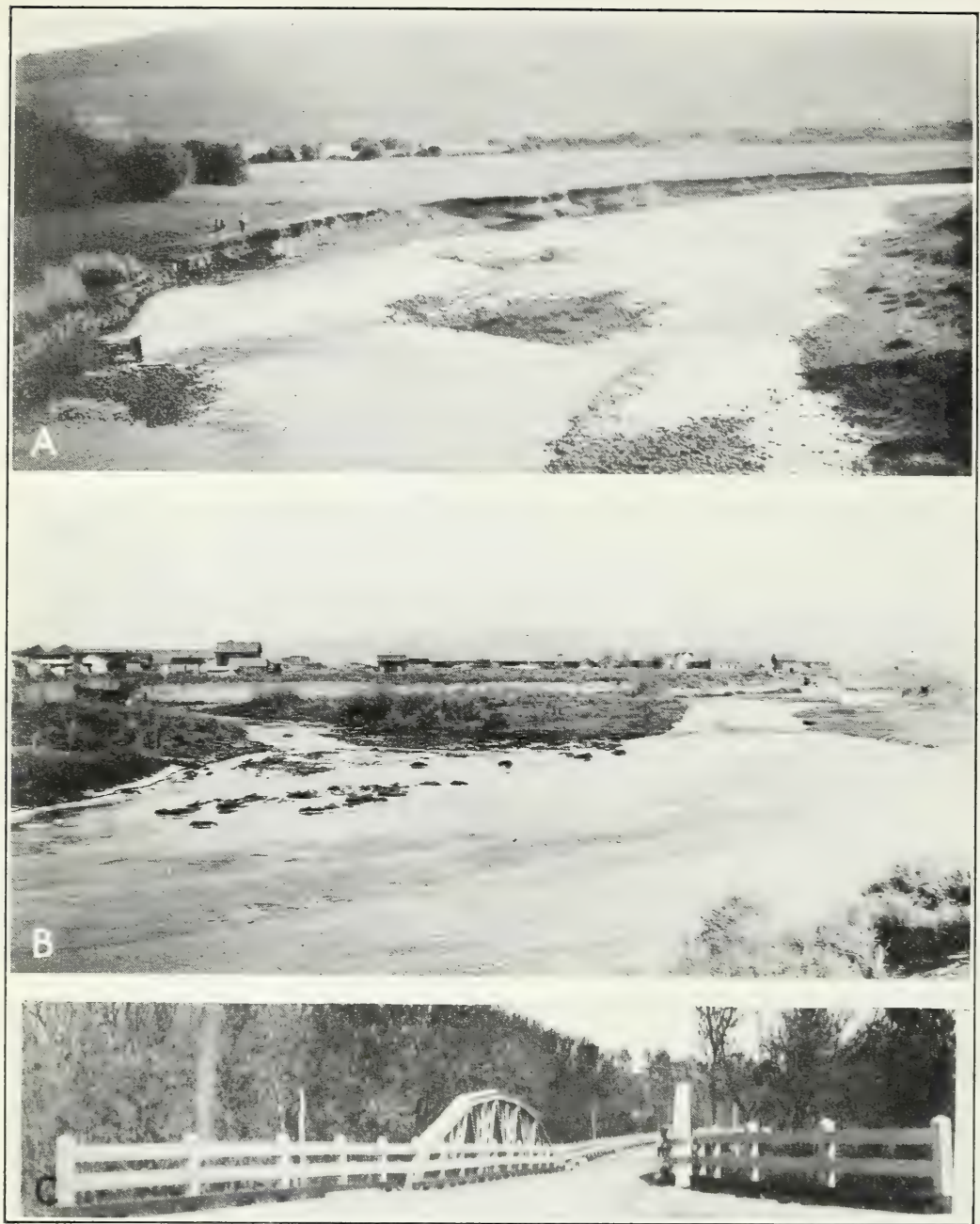

\section{Streams With Unstable Channels and Banks Subject to Erosion}

A.- Streams with insufficient fall to transport material delivered by their tributaries become filled with gravel and sand bars. These deflect the current against the banks with resulting erosion. In this case the current is being deflected against the left bank and the bend is gradually being accentuated

B.-A typical meandering stream. Flood currents have from time to time deflected against the left-hand bank causing marked erosion, as shown, and converting a portion of the left bank into an island. Note that the left-hand channel current is nearly at right angles to the current in the main channel. Cross currents and eroding tendencies of this kind are peculiar to streams in this stage of development

\section{InCORRECT GRADE-LINE TREATMENT}

C.-The concave vertical curve on the approach in combination with the cambered truss gives the optical effect of sag and weakness 
points, and preparing estimates of cost for the necessary wing dams, revetments, dikes, retards, and other control and protection work necessary at the various possible sites, balancing the cost of all such protection work against the cost of spanning the entire flood plain and letting the stream run where it will. If a comparatively narrow point in the flood plain can be utilized, this last method may prove the cheapest solution. The effect of unchecked channel movement is clearly illustrated in Plate 3, A. Plate 3, B illustrates the usial zigzag current effect produced by wing dam installations. The crosscurrent effect induced by the formation of sand or gravel bars is indicated in Plate 4, A. Plate 4, B illustrates a further stage of development wherein the bars have been converted into permanent islands and channel currents are deflected thereby.

Figure 16 is a map of the Willamette River at Harrisburg, Oreg., showing the position of this stream in 1894, 1909, and 1923. This stream may well be taken as exemplifying the characteristics of shifting stream channels above described. The stream itself flows

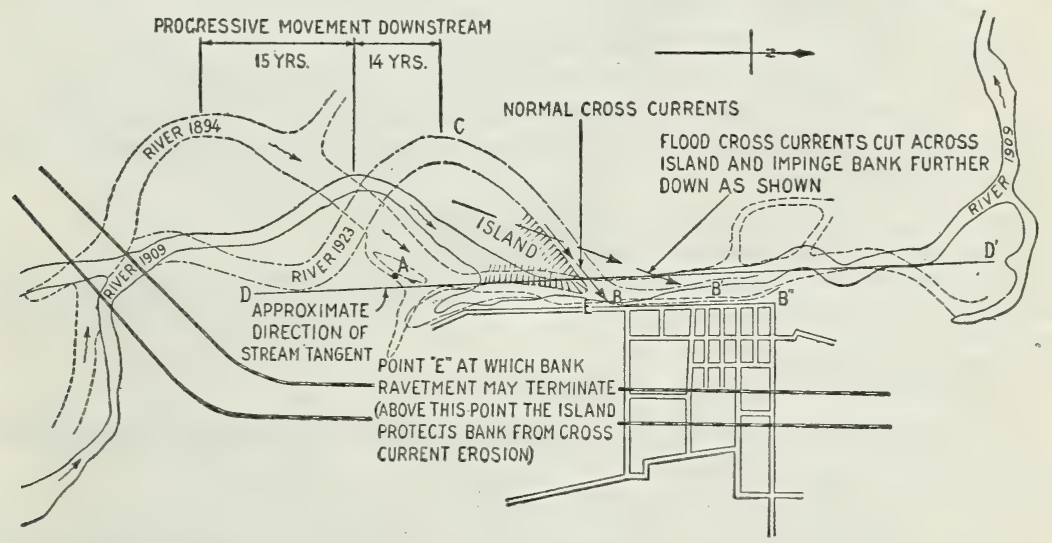

FIG. 16.-The Willamette River at Harrisburg, Oreg., has a shifting channel which presents a difficult problem in bridge location

in a broad flood plain and is fed by mountain tributaries which deliver to it during flood periods more load than it can carry without erosion. The formation of bars at points of low velocity and the constant shifting and changing of the channel is, therefore, greatly accentuated, especially along the upper reaches of the stream.

A drawbridge crossing the river somewhere near point B is now under consideration and the writer has made a rather extended study of the stream in this connection. The high bank on the east shore is subjected to the eroding action of cross currents at B, but at high water these currents shift in direction as indicated, impinging at $\mathrm{B}^{\prime}$. It thus seems advisable to place a bridge structure above $\mathrm{B}^{\prime}$ in order to place the bank erosion at flood periods, below rather than above the structure. As against this argument, it will be observed that the tangent $\mathrm{D} \mathrm{D}^{\prime}$ has for the last 29 years been progressing steadily northward, so that a location at $\mathrm{B}^{\prime \prime}$ would be more apt to remain intact for a longer time. The curved bank $\mathrm{CB}$ is undoubtedly going to progress downstream or northward, endangering the roadway and also the 
approach on the west end. A heavy revetment or a series of wing dams between $\mathrm{C}$ and $\mathrm{B}$ will be needed for the location at $\mathrm{B}$. On the other hand, if the structure is placed at $\mathrm{B}^{\prime \prime}$, a revetment is needed from $\mathrm{B}^{\prime \prime}$ to $\mathrm{E}$, which is much more costly than for one from $\mathrm{B}^{\prime}$ to $\mathrm{E}$. Cutting a channel through at point A looks like a possible plan, but there is always the possibility that this would so increase the gradient of the stream that further erosion along the east bank would result. This would damage the village of Harrisburg to a great extent. There are many arguments to abvance for different locations and different methods of procedure. The point to be emphasized, however, is the necessity for a great deal of preliminary field work and preliminary study before locations are made across meandering or shifting streams.

\section{EFFECT OF ICE AND DRIFT}

Ice jams or gorges are apt to be destructive to bridges not only because of the tendency to erode at banks and around footings, but also because such gorges form a great dam holding back the water until it reaches a height sufficient to break through the ice, whereupon it rushes upon the structure with destructive force. Ice and drift dams of this kind are to be feared at bends or kinks in the stream or at points of constriction of stream banks, and this feature should be thoroughly looked into. The following points should also be taken into consideration:

Water stage at which ice jams are to be feared.

Maximum probable vertical reach of ice jams.

Will the formation of jams above the site operate in any way to deflect the currents from their natural course or to increase the tendency to bank erosion at any point.

Frequency of jams.

Possible protection against effect of ice.

In the matter of drift the following points should be considered:

Character and size of drift.

Position of drift in channel at flood stage.

It has been observed that in the majority of cases the greater volume of drift passes through the thread of the channel. At certain points this may be the approximate center of the stream, whereas at other points drift may hug one of the banks. Back-water currents, eddies, and secondary currents may be such as to pile up drift at some particular point or against a pier location. Where the structure is to be on a continuous grade, from end to end, it may be possible to locate it in such manner that the drift will be carried under the spans on the high side, thus giving a little more clearance. For example, in Figure 17 are shown two possible crossings of a river paralleling a city street which fixes the bridge grade on the right. At $A$ the drift hugs the left bank, making it possible to secure a greater clearance between the lower chord and the projecting roots and limbs of logs and trees than is possible at $B$, since at this point drift tends to hug the right-hand bank. If the main river crossing is 1,000 feet wide and if the street grade is the same at C and D, a 2 per cent grade will give at least 10 feet additional drift clearance for line A.

Velocity of drift.-There are certain locations where it becomes nearly impossible to avoid placing the lower portions of arch ribs or even truss chords slightly below extreme flood water. Such a pro- 
cedure is, of course, not the best practice and should in general be avoided. If this is impossible, the impact stresses due to drift and ice must be calculated and provided for in the design. Where this is to be done, a study should be made of the direction and strength of flood currents and advantage taken of any slack water or eddy which will operate to maintain comparatively still water at the point where arch ribs or other structural members are submerged.

Whether this dipping of chords or ribs below extreme flood level, as above described, should receive serious consideration, will of course depend in a large degree upon the frequency of high water and probable recurrence of extreme floods. In this connection, a study of the character of watershed may prove of value. As more and more of the watershed is put under cultivation each year the
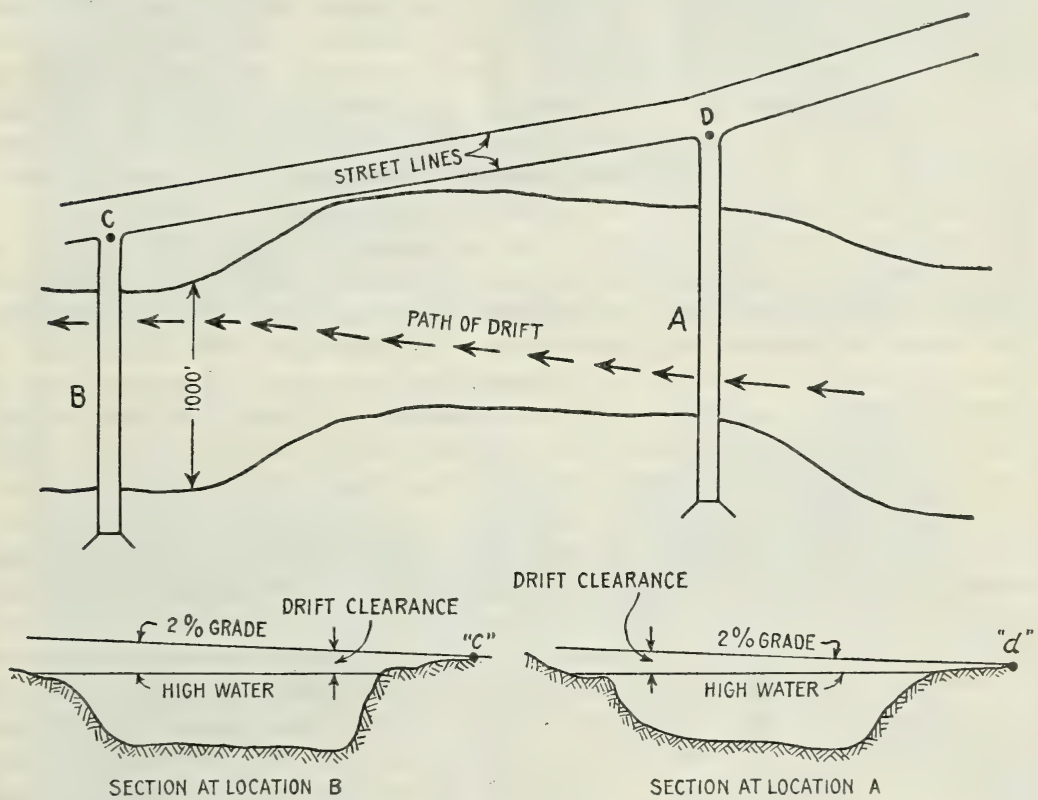

Fig. 17. - Location where a street fixes the elevation of one end of bridge and drift clearance must be secured. Crossing A gives much greater clearance than crossing B

greater will be the proportion of rainfall absorbed through percolation, thus lessening the immediate run-off and decreasing the height of flood water. Forest denudation, on the other hand, has the opposite effect and may cause a more frequent recurrence of floods than formerly. As between cut logs and natural drift, the former will generally prove much more destructive, owing to the absence of any limbs, branches, or root mats which act to cushion the blow. For this reason a study of the possibility of future logging operations may yield data which will influence the above decision and thus modify the general location scheme. For some streams in forest areas, the greater portion of the cutting has been done and the danger from log rafts or breakage of booms will be a constantly decreasing one. For other locations, this contingency must be considered and provided for. 
Navigation requirements have an important effect on the minimum rertical clearance which may be adopted and this in turn ritally affects the location. It is not possible to provide against runaway boats and ships but in many cases clearance for barges through not only the closed morable span, but also under the adjacent fixed spans mas be provided at but slightly increased cost by a proper location.

\section{ALIGNMENT CONSIDERATIONS}

A highwar location, especially through rough country, must parallel waterway and ridge lines for a major portion of its length. A crossing of a waterway, canyon, or ravine, therefore, generally involres an approach alignment down one side of the canyon, crossing the stream or canyon and up on the other side, either doubling back or proceeding ahead. If the line after crossing the canyon doubles back upon itself to gain distance, it is in many cases impossible to eliminate crurature from the bridge approaches except at a prohibitive expense. If, on the other hand, the location proceeds across the canyon and on in the same general direction, some of the curvature may be eliminated by the selection of a skew crossing.

Currature is particularly to be aroided on the approaches of bridge structures because of certain structural difficulties involved. With the high-speed motor rehicle traffic most of the States have for some time superelerated curres as standard practice and lack of supereleration is considered an element of danger. A superelerated bridge approach involves the construction of hand railings, which must be either out of plumb or else not perpendicular to the deck. If such railings are placed perpendicular to a superelevated deck, thus being canted out of the vertical, it gives an appearance of sag and incorrect alignment. If, on the other hand, the railings are placed in a rertical plane, the inner rail obstructs the roadway clearance by an amount equal to the height of the railing multiplied by the sine of the angle of superelevation. This clearance restriction is, of course, very small, but may be just sufficient to expose the rail cap to impact from rehicles. Cases have been observed where concrete railings of this type are seriously marred, chipped and broken, owing to the abore cause. (See pl. 5, A.) The problem involves the balancing of approach curvature with its undesirable details against the additional expense and general undesirability of a skewed crossing. If the skewed crossing is particularly undesirable because of stream conditions, or if the location is such that skewing the bridge will not reduce approach currature, it may be necessary to consider throwing the approach alignment on either side back into the hill in order to obtain a requisite tangent length for the structure. This procedure generally involves an increase in the cost of the line and in many cases necessitates increasing the rate of curvature away from the bridge.

On many bridge crossings aroiding currature is a difficult matter and inrolres a substantial increase in the cost of the line. In such cases considerable time may be well spent in careful and painstaking preliminary study. The location is perhaps the most permanent part of a highway system.

For a bridge of any size it should be considered that the location is to be fixed for all time to come and that if any error is made the 


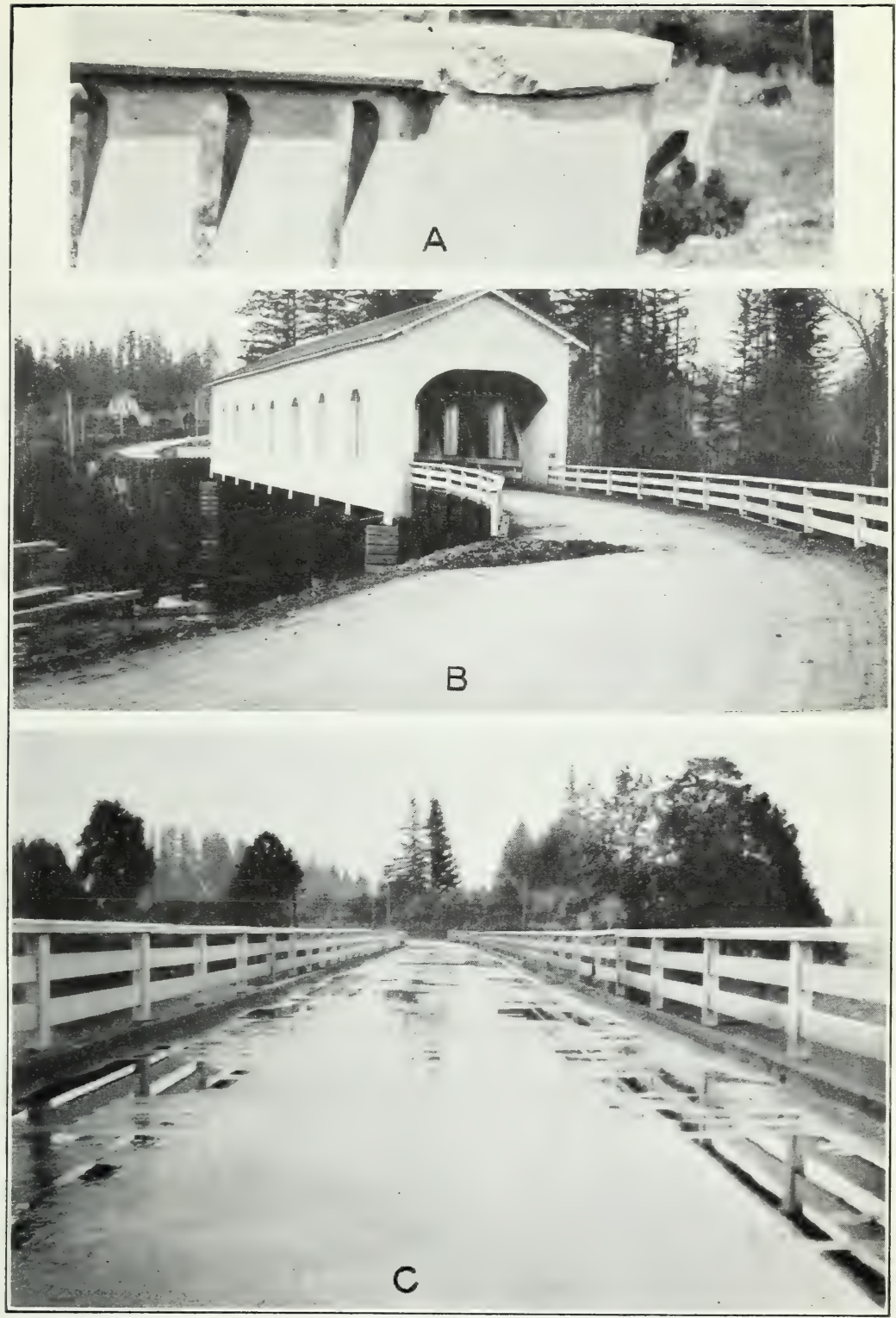

Rail Clearance, Sight Distance, and Grade-LINE Treatment are all

A.-Superelevation of the bridge floor may expose a rail to impact from vehicles causing damage as illustrated

B.-An example of poor bridge location and improper selection of type. To avoid a slight increase in span length, the locator has thrown excessive reverse curvature into the approach alignment. This coupled with the use of housed timber-truss construction restricts the sight distance. At a slight increase in cost a much better alignment could have been obtained and the use of steel-truss construction would have greatly improved the clear sight distance

C.-Poor floor drainage resulting from lack of camber 


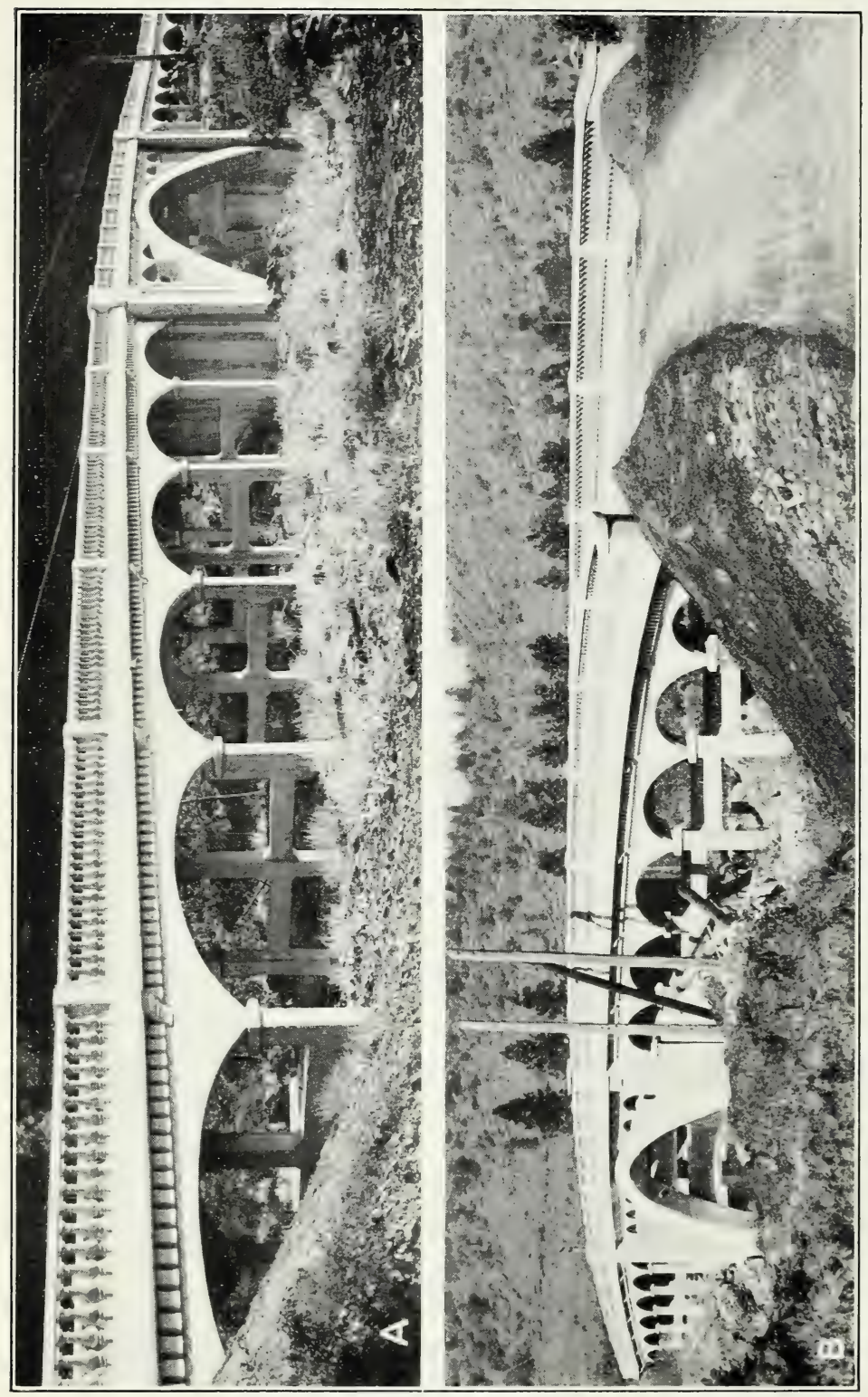

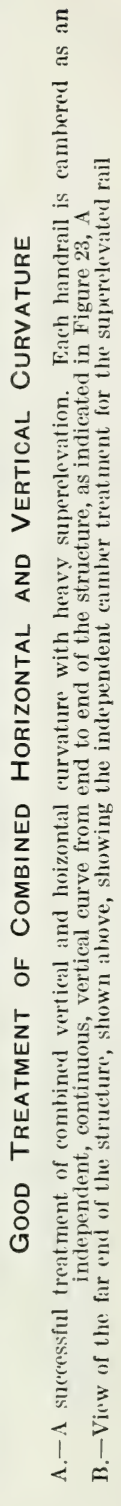


public will continue to pay the penalty indefinitely. The feeling is prevalent among engineers that massive concrete work will last for many centuries. In building this type of substructure, therefore, the location problem becomes a paramount issue and should be given much more study than has often been the case in times past. Plate 5, B illustrates the tendency, so frequently observed, to utterly disregard considerations of traffic service and safety and to place the bridge structure with regard for but one consideration-viz, low first cost.

\section{GRADE-LINE TREATMENTS}

The grade line adopted for any highway bridge structure has an important bearing on its utility and appearance, more especially the latter. There are certain things which can be done and, from the standpoint of appearance, certain things which can not be done with a bridge grade line. In rolling country practically every other vertical curve will be concave upwards. On the highway proper this treatment is not objectionable in appearance and unless drainage conditions interpose may be considered good practice. On bridge structures, however, a concave grade line invariably presents the appearance of sag in the railing and weakness in the structure. It is, therefore, highly desirable that grades be so chosen as to approach the structure proper from each direction on an ascending grade. In general, it has been found that camber on bridges can be introduced more effectively by springing a long vertical curve from end to end of the structure than by the use of any fixed camber diagram or table.

It is also desirable to have the approaching grade lines intersect at a point as near as possible to the center of the bridge in order to make the appearance symmetrical. The elimination of concave vertical curvature is doubly necessary in cases where the horizontal alignment is not all tangent. It is impossible to combine inverse or concave vertical curvature with horizontal curvature without entirely ruining the appearance of the structure. No matter how straight and true the alignment of the handrail, the concave or inverse vertical curve in combination with the horizontal curve will introduce an optical illusion of reverse curvature in the railing, so that the appearance of the structure is completely ruined. More and more are engineers and public officials coming to appreciate the necessity for pleasing and correct æsthetic or architectural treatment in highway construction. For bridge structures, the appearance depends on the structural lines rather than the texture, and in no one point can the appearance of the bridge be more completely made or marred than in the treatment of the grade line. The optical effect resulting from different combinations is a matter warranting the most careful and painstaking study. The ancient Greeks and Romans, whose architecture has withstood the criticism of 20 centuries, gave a prominence to this phase of design which has been more or less lost sight of in modern times. The broad, majestic, circular steps which add so much to the appearance of many of the ancient edifices, are in reality not flat and level tables, as they appear to be, but are warped at the ends just sufficiently to counteract the foreshortening of the perspective and thus create the optical impression of a truly level plane. This is one of many examples illustrating the tendency in ancient architecture to take cognizance of optical illusions and artificially 
counteract them. In contrast to these truly artistic creations, a day's drive in any section of the United States will disclose examples of expensive and otherwise handsome concrete-bridge construction, seriously marred, if not completely ruined in appearance, by unfortunate combinations in alignment and grade-line treatment. Plate 6 illustrates a correct grade-line treatment and Plate 4, C illustrates the bad effect produced by the use of a concave grade line.

The following circular letter, issued from the writer's office in 1921 covers the essential requirements as regards camber and grade-line treatment. Inasmuch as the grade line chosen has an important bearing upon the alignment, this information should be available and should be carefully studied at the time the preliminary location for the structure is run in on the ground.

\section{To All Resident Bridge Engineers:}

In order that practice in regard to camber and grade lines on bridge structures may be uniform and in order that grade lines over and adjacent to bridge crossings may be laid to conform and harmonize with camber requirements, the following general instructions are issued herewith. These instructions are for the guidance of locating engineers, division engineers, designers, draftsmen, and resident engineers on construction.

Camber is placed on bridge structures in order to facilitate the removal of surface water from the deck (see pl. 5, C) and for appearance. For wooden struc-

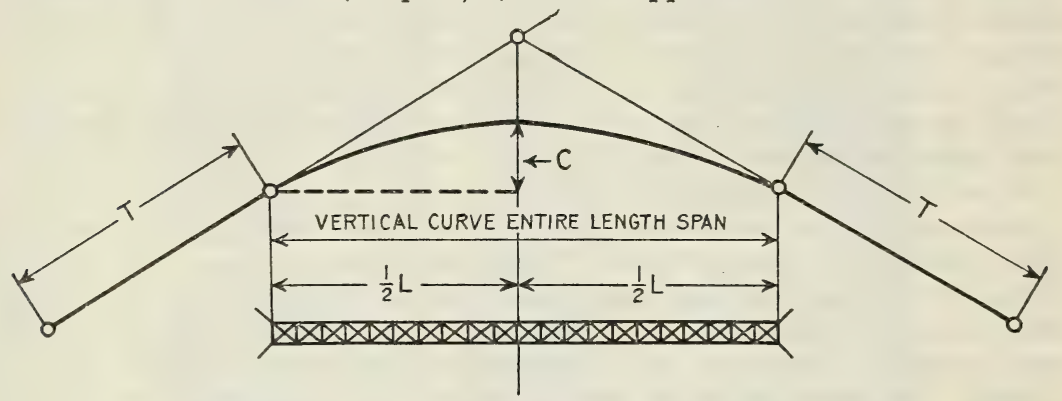

FIG. 18.- Treatment of grade line on bridge for a convex intersection of grades

tures, camber has a further value in that it affords a certain amount of leeway so that shrinkage of the timber and seating of the joints will not cause a sag or water pocket in the deck.

There are three dangers which must be avoided in the grade line over any bridge, as follows:

1. A concave grade line.

Experience has shown that it is impossible to properly drain the structure or to produce a satisfactory appearance on a bridge rail where any portion of it is concave. Where necessary to adopt a concave vertical curve, as shown in Figure 22, such curve must always be placed on the approach fills and not on any portion of the structure.

2. Too much camber on flat grades.

The camber should be sufficient to provide adequate drainage and to remove any flat or hollow appearance in the rail, but not so marked as to cause the structure to appear humped.

3. Insufficient amount of camber on timber truss spans.

The camber for this type of structure must be sufficient to take up all shrinkage and settlement at the joints.

The following grade-line treatments are recommended:

CASE 1. CONVEX INTERSECTION

This arrangement of grade lines as shown in Figure 18 is the most desirable arrangement possible. The ascending grades should be equal or as nearly equal as possible and the vertex should lie over the 
center of the bridge or as near the center as possible. The length of the tangent $\mathrm{T}$ should preferably be not less than 200 feet. The camber $\mathrm{C}$ for this type of grade treatment will be as required by the vertical curve and will be the same for all types of construction. The vertical curve should not, in general, be shorter than the length of the bridge and not less than that required by other standards. For structures

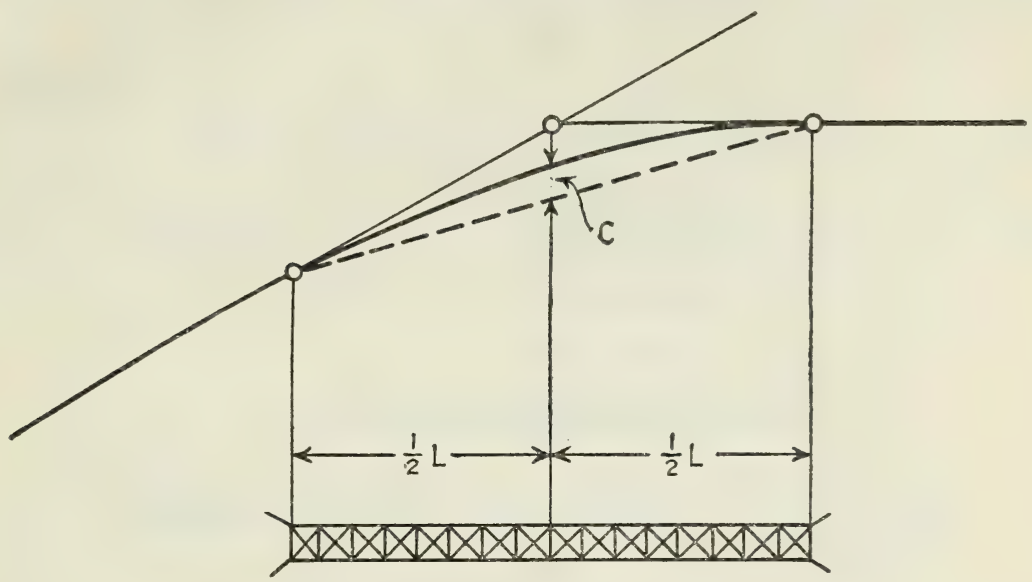

FIG. 19.-Treatment of grade line where the grades on each side of the vertex are unequal in amount but the bridge can be centered under the vertex

exceeding 800 feet in total length, certain clearance and grade point restriction may render it necessary to extend the tangent $T$ partly onto the structure. This is to be avoided, however, if it can be done without prohibitive cost.

If it is impossible to lay the approaches on equal grades, a treatment as shown in Figure 19 may be adopted. This type of grade line

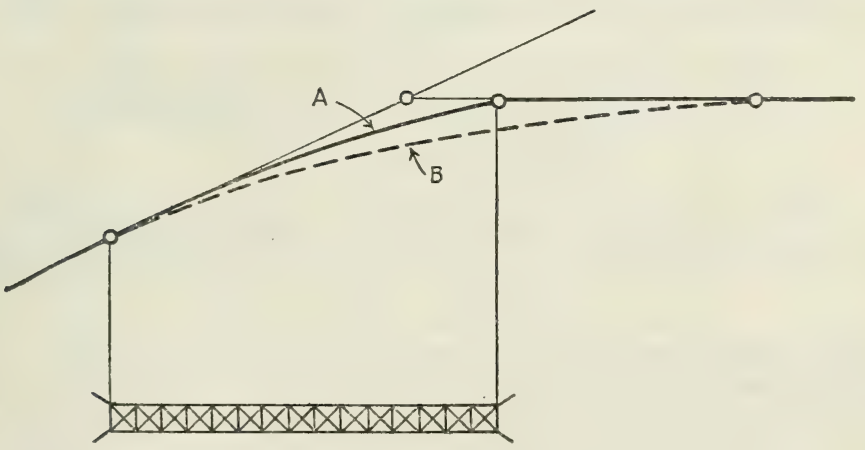

FIG. 20.-Treatment of grade line where the grades on each side of the vertex are urequal in amount and the bridge can not be centered under the vertex

should not be used unless absolutely necessary. If impossible to center the vertex over the bridge, a treatment as shown in Figure 20 may be adopted. In this case, the vertical curve may be made symmetrical and the bridge placed on any portion of it as shown by line $\mathrm{B}$ or an unsymmetrical vertical curve may be worked out as shown by line $\mathrm{A}$. 
CASE 2. STRAIGHT GRADE LINES, EITHER LEVEL OR INCLINED

In this case, the bridge grade is raised parallel to itself a distance $a$ and an arbitrary camber placed on the structure. The approach rertical curves should be not less than one-fourth of the length of the structure, unless this length exceeds 200 feet, in which case the

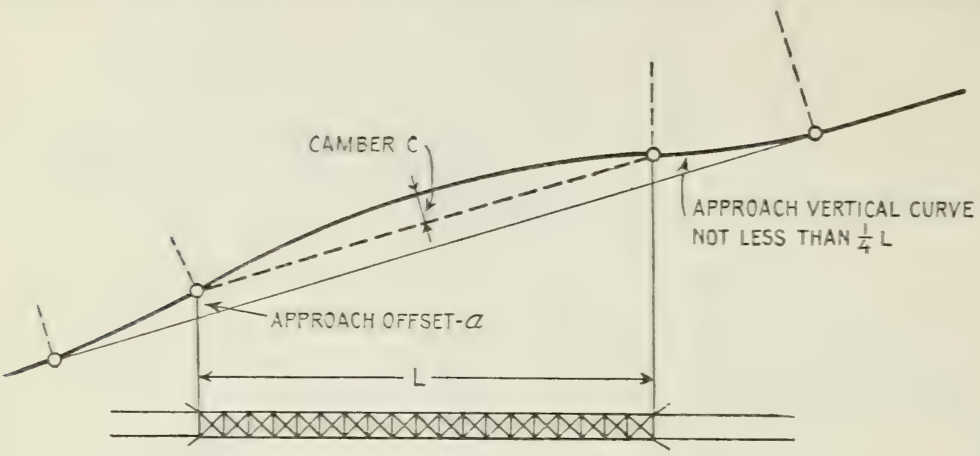

ON GRADES OF 3 PER CENT AND UNDER $C=1$ INCH PER 40 FEET OF SPAN LENGTH.ON GRADES OVER 3 PER CENT REDUCE CAMBER 50 PER CENT FOR EACH ADDITIONAL PER CENT OF GRADE.

FIG. 21.-Grade-line treatment of bridge located on a continuous grade

approach rertical curre should be kept at 200 feet and the camber $c$ should be giren a ralue equal to 1 inch for everv 40 feet of span length. There the grade is more than 3 per cent, the camber should be reduced as shown in Figure 21.

\section{CASE 3. CONCAVE GRADE INTERSECTION}

A flat bridge grade should be laid to intersect the two intersecting approach grades, as shown in Figure 22, and connected to the profile

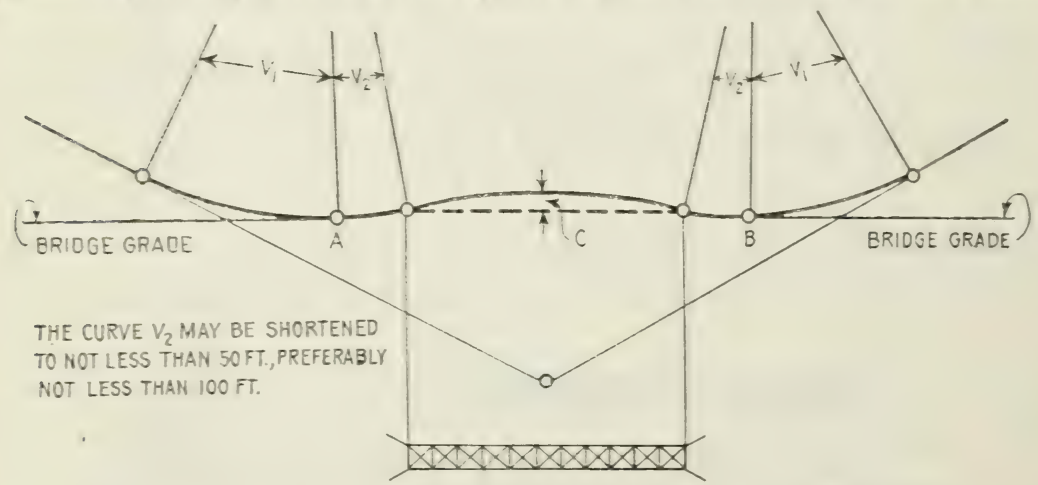

FIG. 22.-Grade-line treatment on a bridge located on a concave grade intersection

grades with rertical curres. The treatment between points $\mathrm{A}$ and $\mathrm{B}$ should be exactly the same as for the flat grade line (fig. 21), except that the camber $c$ should be taken as 50 per cent of the camber outlined under case 2 and the rertical curves $V_{2}$ may be shortened to not less than 50 feet if necessary. 


\section{HORIZONTAL ALIGNMENT}

The above has to do with vertical alignment only. As regards horizontal alignment, bridge structures should always be located on tangent unless absolutely unavoidable.

The building of handrails on curved alignment either in concrete or in timber requires more difficult framing, more difficult and expensive form work, and is consequently more costly. For timber rails, it is also much more difficult to maintain true alignment on account of the buckling tendency owing to the shrinkage and warping of the timber.

For concrete structures, superelevation on curves necessitates that the form work for each panel be different, thus increasing the labor cost and resulting in a higher unit price:

For covered truss spans, the question of sight distance enters. Under no circumstances should a covered bridge be built on any alignment which is not tangent entirely across the structure and for a distance of preferably not less than 200 feet, and in no case less than 100 feet at either end of the bridge.

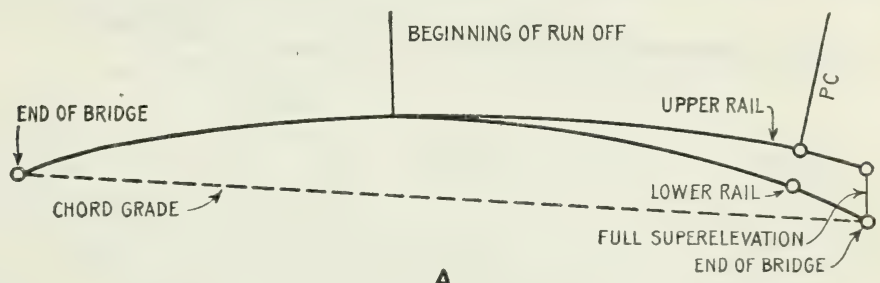

END OF BRIDGE

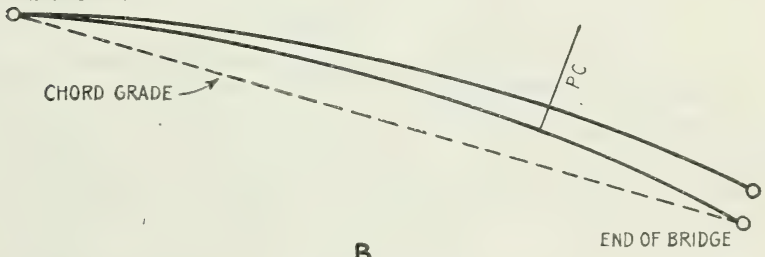

FIG. 23.-Treatment of bridge rails where horizontal curvature requires superelevation. The treatment shown in $\mathrm{A}$ is the most desirable if the camber permits, but that shown in B may be necessary if the camber is small.

\section{STRUCTURES ON CURVES}

The maximum length for the individual spans in any bridge which should be built on any curve is given by the expression $L=\frac{200}{D}$ where $L=$ length of span and $D=$ degree of curvature.

Where it is impossible to eliminate curvature on a bridge and where superelevation must be provided, each side should be treated separately, as shown in Figure 23, A, in such manner that both rails will take a continuous convex curve from end to end. Where there is sufficient camber to allow it, the treatment shown (fig. 23, A) is to be used. Where there is not sufficient camber, the treatment shown in Figure 23, B will be necessary in order to avoid the concave line shown in Figure 24, A.

The superelevation is increased from the zero point (either at the vertex, as shown in Figure 23, A, or at the far end of the structure, as shown in Figure $23, \mathrm{~B}$, to a maximum value at the end of the 
structure. If the P. C. of horizontal curvature falls on the structure, full superelevation is not obtained at the P. C. If the P. C. falls just outside the structure, the superelevation at the end of the bridge is less than the superelevation which will be obtained at the P. C. If the P. C. falls within the limits of the structure and if full superelevation must be furnished at this point and carried along the remaining portion of the structure at this same value, a special treatment will be necessary.

For bridges lying adjacent to, or partially on horizontal curves at either end, having opposite directions, a treatment, as shown in Figure $24 \mathrm{~B}$, should be adopted, each rail being given a smooth continuous curve from end to end. For structures having curves at either end in the same direction, full superelevation should be carried across the bridge, the rails being treated as separate parallel curves.

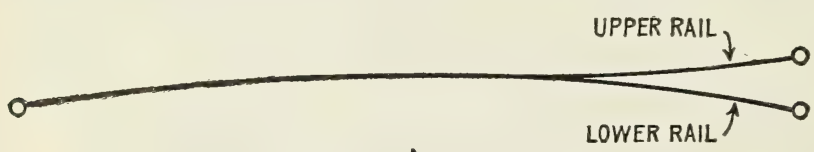

A

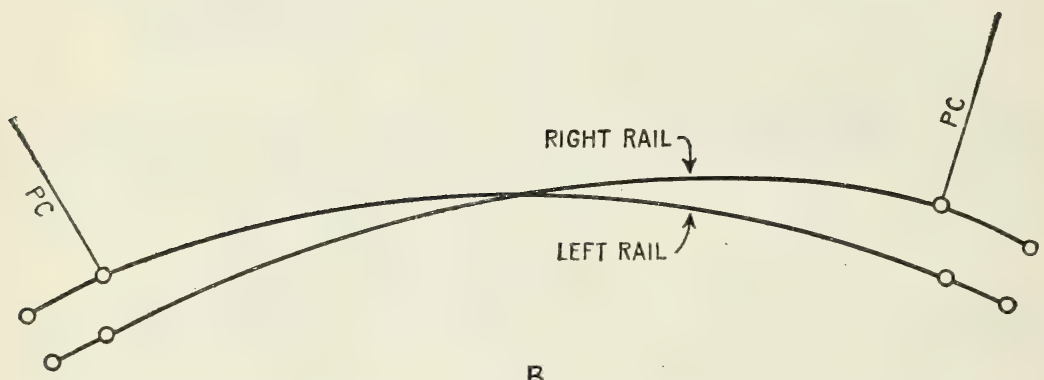

B

FIG. 24.-A shows an improper method of rail treatment in superelevating the roadway which gives an appearance of sag. $\mathrm{B}$ shows a correct treatment of rails where the bridge is either on or adjacent to curvature in opposite directions at the ends

\section{TRAFFIC INFLUENCE ON BRIDGE LOCATION}

It may be stated as a basic principle, that the location of any bridge structure should be such as to render the maximum service to traffic at minimum cost. Cost considerations have already been discussed in this connection but certain traffic influences controlling the selection of site should be mentioned.

A highway bridge, to give the best possible traffic service, must be located at the best possible routing point, and in this connection it, may be well to consider separately three principal types of traffic through, regional, and local.

\section{THROUGH TRAFFIC CONSIDERATIONS}

Under this head should be listed considerations involving the following:

National defense.

Movement of troops and munitions.

Safety from enemy attack.

Ability to protect bridgeheads. 
Objectives for through routing.

Service to pleasure resorts.

Capitalization of natural scenic beauty spots.

Service to natural through traffic trading points.

Mileage considerations.

Selection of the shortest possible routing for through traffic consistent with maximum service, as above outlined.

\section{REGIONAL TRAFFIC CONSIDERATIONS}

Industrial traffic service will be the most efficient where centers of production of raw material are connected by direct routing with their natural points of distribution, and where the centers of industry (mills, factories, etc.) are connected directly with the local supply of raw material.

Pleasure traffic will be best served by direct connection of urban centers with natural pleasure resorts (taking into consideration, of course, the trend of future development).

\section{LOCAL TRAFFIC CONSIDERATIONS}

Maximum service to local traffic is obtained where traffic congestion is reduced to a minimum. Under this head falls the consideration of traffic loops, distribution plazas, etc. The question of traffic distribution at bridge terminals will be discussed in more detail elsewhere. However, in selecting the location of any bridge structure contiguous to an urban center, provision for such distribution and collection facilities, either present or future, should receive consideration. As illustrative of the foregoing, consider the plan shown in Figure 25, which shows a bridge crossing adjacent to a natural municipal traffic loop. For traffic originating or terminating within the loop, location $\mathrm{C}$ will best serve. This is also the most desirable location for traffic surrounding the loop if of equal density on all sides. If, on the other hand, a main trunk road is located as shown at $\mathrm{F}$, the bridge may well be placed at location $\mathrm{A}$ to route through traffic out of the congestion at the loop. It may even be necessary to construct a ramp or diagonal graded approach at D to separate traffic quickly at the bridge head. If a large volume of traffic desiring to cross the stream enters the loop from the south at point $\mathrm{E}$, then location $\mathrm{B}$ might receive consideration.

In this discussion no attempt has been made to discuss and list all of the traffic problems involved in the selection of a bridge site nor to attempt to suggest a definite solution as this is a matter which can only be worked out for each individual case on its own merits.

\section{LOCATION OVER NAVIGABLE WATERS}

Perhaps the first and most important question to decide in locations over navigable waters is the choice between a high level structure and a structure provided with a movable channel span or spans. Again the basic principle of maximum traffic service at minimum cost may be stated as the controlling principle, but in this case service to water traffic as well as land traffic must be considered. Water transportation is best-served by a high-level structure giving a vertical clearance sufficient to permit the passage of such water craft, present and future, as may operate over the waterway considered. Highmasted schooner traffic will require a vertical clearance of 140 to 
160 feet and for the largest naval craft perhaps even a greater clearance. Ordinary river traffic can generally be accommodated by a vertical clearance of from 60 to 80 feet above maximum boating stage.

If a true high-level location (employing fixed spans) is not feasible, a structure on a grade such that openings are required only for the highest masts will be more desirable in that the greater portion of the craft using the waterway can pass under the closed channel span or perhaps under adjacent fixed spans without the delay incident to "standing off" for the draw to open.
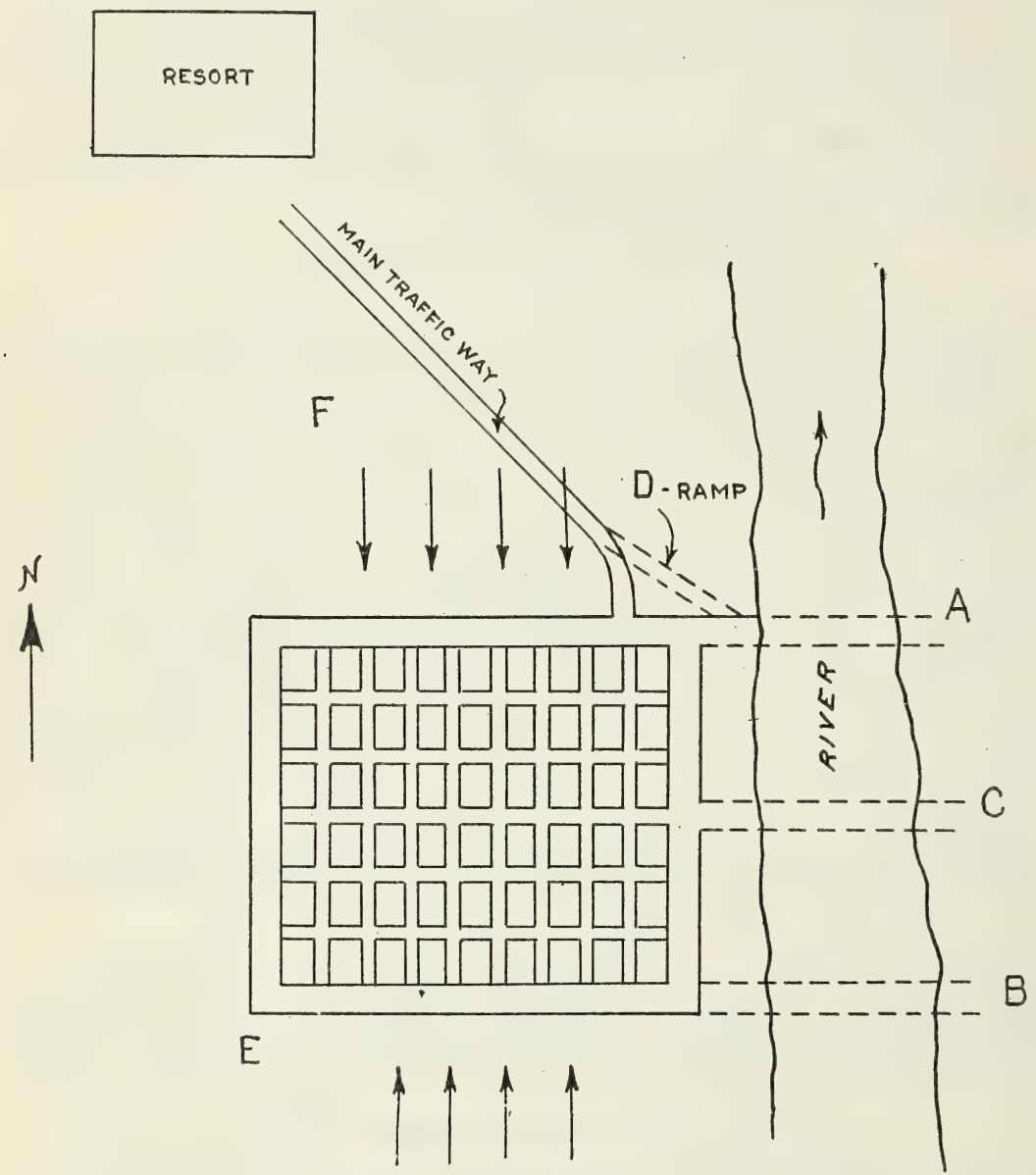

FIG. 25.-Desirable bridge locations under various traffic conditions adjacent to a congested traffic district

From the standpoint of land traffic, a movable span will generally involve shorter approaches, a more direct connection with industries located on the river front and less grade. On the other hand, the delay to land traffic due to closure of the roadway during the operation of the movable span will generally be a considerable item. Some of the bascule spans in the city of Chicago open an average of seventy-five times per day. At a conservative estimate, this closes the crossing for three hours during the day. Assuming the bulk of traffic as being 
carried during 15 of the 24 hours, the traffic-carrying capacity of the structure is reduced 20 per cent. The results of the introduction of a movable span on a busy bridge, especially if the waterway traffic is such as to make the bridge active, is obviously a congestion of traffic back of each gate. This congestion may extend back across lateral streets, blocking them and creating at times a rather chaotic condition, especially during the handling of exceptionally heavy traffic.

From the standpoint of cost, in the majority of cases the low-level structure, even with the expensive movable span, machinery, power equipment, etc., will be cheaper in first cost than the high-level structure with its long approaches and high piers or towers. For highlevel structures in cities and towns, it is also rather difficult to avoid heavy property damage to the property fronting on the street between the harbor line or river front and the point at which the high-level approaches come to grade. There is also the question of transriver traffic originating or terminating on the river front which will be compelled to travel a more devious path with a high-level crossing than with one whose grade coincides with the grade of the river-front streets.

As regards maintenance and operation costs, the high-level structure has a marked advantage. The following tabulation of operation cost for three typical months for the Morrison Street bridge over the Willamette river, at Portland, Oreg., will be of interest in this connection.

\begin{tabular}{|c|c|c|c|}
\hline Month & $\begin{array}{l}\text { Num- } \\
\text { ber of } \\
\text { open- } \\
\text { ings }\end{array}$ & $\begin{array}{l}\text { Total } \\
\text { time } \\
\text { open }\end{array}$ & $\begin{array}{l}\text { Cost of } \\
\text { operation } \\
\text { (labor } \\
\text { only) }\end{array}$ \\
\hline $\begin{array}{l}\text { January, } 1920 \\
\text { July, } 1920 \\
\text { December, } 1920\end{array}$ & $\begin{array}{l}614 \\
880 \\
748\end{array}$ & $\begin{array}{ll}\text { h. } & \text { m. } \\
38 & 59 \\
52 & 25 \\
46 & 23\end{array}$ & $\begin{array}{r}\$ 1,247.50 \\
1,826.21 \\
1,360.00\end{array}$ \\
\hline Average & 747 & $45 \quad 56$ & $1,477.90$ \\
\hline
\end{tabular}

It will be observed from the above that not only does this draw span obstruct traffic on the highway about one and one-half hours per day, but the labor cost of operation will capitalize at 5 per cent to $\$ 354,696$. At a conservative estimate, therefore, a high-level structure is worth $\$ 300,000$ more at this point from a standpoint of economy alone.

If a movable span is to be used there are several points which deserve careful study when the location is made, among which may be listed the following:

DIRECTION AND VELOCITY OF CURRENTS, CROSS CURRENTS, AND TIDAL FLOWS AS AFFECTING THE HORIZONTAL CLEARANCE REQUIRED

In Figure 26 the general direction of the river is along the line $\mathrm{C} \mathrm{C}$ so that from casual inspection either of the locations shown crosses the waterway at nearly a right angle. Tidal currents have determined a boating channel, however, which hugs the north bank at the crossing of line $\mathrm{A}$ and is rather pronouncedly skewed with this location. At this crossing the movable span (which is always the most 
expensive portion of the bridge) will for equal navigable capacity, need to be of a length given by the formula

$$
\mathrm{L}^{\prime}=\frac{L}{\cos \phi}+W \tan \phi
$$

as shown in Figure 26. It will also be observed that line A places the movable span near the north bank and if the grade is fixed by certain

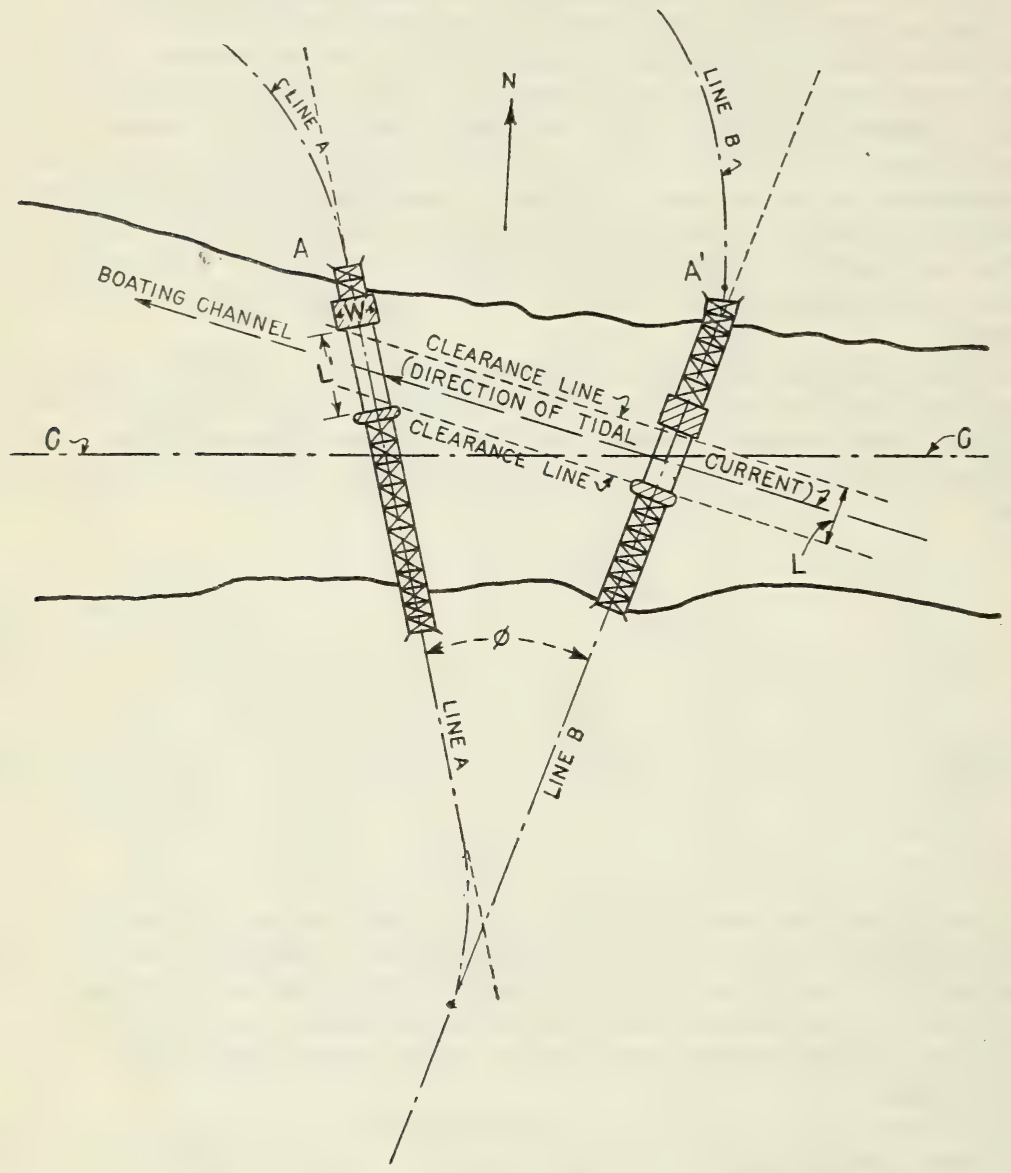

FIG. 26.-The effect of current direction on location and length of movable span

bank points $A$ and $A^{\prime}$, as is very apt to be the case, it will not be possible with the same ruling grades to place the movable span as high on line $\mathrm{A}$. This means a more active bridge at line $\mathrm{A}$ and $\mathrm{a}$ greater inconvenience to traffic.

The above is but one of many instances illustrating the need for special care in preliminary location study for navigable crossings.

At best the navigation of a large boat through the comparatively restricted horizontal opening afforded by a movable span is a task requiring skill and judgment. Complicate this by a location where 
strong cross currents prevail at any boating stage or where any natural or artificial constriction causes a heavy tidal current and the necessity for additional horizontal clearance for the same degree of navigability is apparent.

\section{WIND CONDITIONS AS AFFECTING HORIZONTAL CLEARANCE REQUIRED}

Certain portions of a bay or broad river are observed as being comparatively quiet at nearly all seasons of the year, while other portions of the same waterway immediately adjacent will run white caps under the slightest wind. The difference in behavior at these points is doubtless the result of natural wind currents, and is controlled by the adjacent topography. It does not need to be emphasized that greater horizontal leeway will be needed in the rough water to provide the same degree of safety for navigation.

\section{ALIGNMENT OF STREAM OR WATERWAY AS AFFECTING SIGHT DISTANCE FOR NAVIGATION}

The location of any bridge structure, whether over navigable waters or not, should avoid sudden bends or changes in the direction of the river channel. In the case of movable bridge spans, however, such a procedure is doubly essential in order to permit water craft sufficient sight distance so that they may be able to observe signals from the drawbridge operator while they are still at a considerable distance from the bridge. A long, straight approach is also necessary in order to enable any tug with a long tow to straighten out before having to attempt the crossing.

\section{DOCK AND WHARF RIGHTS AT THE BRIDGE HEAD}

The location should be such as to afford a minimum obstruction to the use of the river front for docks and wharfage.

\section{ANCHORAGE ABOVE THE BRIDGE SITE}

If it is possible to place the bridge structure above rather than below any large anchorage or group of docking facilities, there will result a great saving in time to both river and land traffic, a small saving in operation cost, and a gain as regards safety to the bridge structure itself. River traffic progressing up the ordinary waterway drops off at each point of dockage. By moving the location of any bridge just above any point of principal dockage, the number of openings is decreased and traffic over both waterway and highway is thus better served. Moreover, if barges are anchored at any point along the stream a location above them obviously eliminates the danger to the bridge structure, should any of these break their moorings during a flood stage on the river (this being an accident which happens with uncomfortable frequency).

\section{CONSTRICTION OF WATERWAY BY FILLED APPROACHES}

For any bridge structure constriction of the waterway is to be avoided on account of the tendency to increase current erosion. For navigable waters it has the further undesirable effect of producing swift water in the channel, rendering navigation that much more 
difficult. If the bottom is soft, the channel is very apt to erode at the bridge, but to shoal below it, thus obstructing navigation.

In general the points above enumerated pertain to the safety and adequacy of the bridge opening as regards the passage of water traffic. It is true that the bridge engineer in general is serving a client or clients who are interested primarily in the safeguarding and service of traffic over the bridge rather than through it. However, the bridge engineer, especially if he be serving as a public official, should be interested not only in the welfare of the particular branch of the State which he serves, but also in that of the public at large and no bridge structure which obstructs and hinders water traffic can be said to truly serve in the development of the country as a whole, regardless of its excellency as a carrier of land traffic.

It seems highly essential and desirable that the bridge engineer view his problem in a broader light than formerly and take into consideration the points enumerated above and any other features which affect the safety of and service to water traffic.

Plans for bridge structures over navigable streams must be submitted to the War Department for approval. The engineers in this department are generally among the highest authorities in the country as regards river and harbor control and improvement. They are jealously guarding the navigable waterways of the country, which Congress has entrusted to their care and will permit of no construction which, in the slightest degree, will hamper or hinder the free and natural use of such waterways (which is, of course, exactly as it should be).

If the bridge engineer in his location does not take cognizance of the interests of navigation, the War Department engineers will do it for him. It will be much better to try to anticipate the viewpoint of the navigation interests and the river and harbor engineers, so that final approval by the War Department can be made with minimum of change.

ADDITIONAL COPIES

OF THIS PUBLICATION MAY BE PROCURED FROM

THE SUPERINTENDENT OF DOCUMENTS

GOVERNMENT PRINTING OFFICE

WASHINGTON, D. C.

AT

15 CENTS PER COPY 


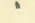


